\title{
THE
}

\section{Legacy and Novel Per- and Polyfluoroalkyl Substances in Juvenile Seabirds from the U.S. Atlantic Coast}

Anna R. Robuck

Mark G. Cantwell

James P. McCord

Lindsay M. Addison

Marisa Pfohl

See next page for additional authors

Follow this and additional works at: https://digitalcommons.uri.edu/gsofacpubs

The University of Rhode Island Faculty have made this article openly available. Please let us know how Open Access to this research benefits you.

This is a pre-publication author manuscript of the final, published article.

Terms of Use

This article is made available under the terms and conditions applicable towards Open Access Policy Articles, as set forth in our Terms of Use.

\section{Citation/Publisher Attribution}

Robuck, A.R. Legacy and Novel Per- and Polyfluoroalkyl Substances in Juvenile Seabirds from the U.S. Atlantic Coast. Environmental Science \& Technology 202054 (20), 12938-12948. DOI: 10.1021/ acs.est.0c01951

This Article is brought to you for free and open access by the Graduate School of Oceanography at DigitalCommons@URI. It has been accepted for inclusion in Graduate School of Oceanography Faculty Publications by an authorized administrator of DigitalCommons@URI. For more information, please contact digitalcommons-group@uri.edu. 


\section{Authors}

Anna R. Robuck, Mark G. Cantwell, James P. McCord, Lindsay M. Addison, Marisa Pfohl, Mark J. Strynar, Richard McKinney, David R. Katz, David N. Wiley, and Rainer Lohmann 
2 Polyfluoroalkyl Substances (PFAS) in Juvenile

\section{Seabirds from the US Atlantic Coast}

AUTHORS: Anna R. Robuck ${ }^{t^{*}}$, Mark G. Cantwell ${ }^{\ddagger}$, James McCord ${ }^{\perp}$, Lindsay M.

Addison", Marisa Pfohß ${ }^{\#}$, Mark J. Strynar ${ }^{\perp}$, Richard McKinney ${ }^{\ddagger}$, David R. Katz ${ }^{\ddagger}$, David N.

Wiley", and Rainer Lohmannt

† University of Rhode Island Graduate School of Oceanography, Narragansett, RI 02882

łUS Environmental Protection Agency, Center for Environmental Measurement and Modeling, Atlantic Coastal Environmental Sciences Division, Narragansett, RI 02882

$\perp$ US Environmental Protection Agency, Center for Environmental Measurement and Modeling, Durham, NC 27709

\# Audubon North Carolina, Wilmington Coastal Office, Wilmington, NC 28411

$\S$ University of Rhode Island, Biomedical and Pharmaceutical Sciences, Kingston, RI 02881

\footnotetext{
" National Oceanic and Atmospheric Administration Stellwagen Bank National Marine
} Sanctuary, Scituate, MA 02066 
${ }^{*}$ Corresponding author: annarobuck@gmail.com

KEYWORDS: PFAS, PFEAs, PFESA, PFECA, PFOS, bioaccumulation, seabirds

21 Per- and polyfluoroalkyl substances (PFAS) are anthropogenic, globally distributed

22 chemicals. Legacy PFAS, including perfluorooctane sulfonate (PFOS), have been

23 regularly detected in marine fauna but little is known about their current levels or the

24 presence of novel PFAS in seabirds. We measured 36 emerging and legacy PFAS in

25 livers from 31 juvenile seabirds from Massachusetts Bay, Narragansett Bay, and the

26 Cape Fear River Estuary (CFRE), USA. PFOS was the major legacy perfluoroalkyl acid

27 present, making up 58\% of concentrations observed across all habitats (range: 11 - 280

$28 \mathrm{ng} / \mathrm{g}$ ). Novel PFAS were confirmed in chicks hatched downstream of a fluoropolymer

29 production site in the CFRE - a perfluorinated ether sulfonic acid (Nafion byproduct-2;

30 range: $1-110 \mathrm{ng} / \mathrm{g})$ and two perfluorinated ether carboxylic acids $\left(\mathrm{PFO}_{4} \mathrm{DA}\right.$ and

$31 \mathrm{PFO}_{5} \mathrm{DoDA}$; $\mathrm{PFO}_{5} \mathrm{DoDA}$ range: $5-30 \mathrm{ng} / \mathrm{g}$ ). PFOS was inversely associated with

32 phospholipid content in livers from CFRE and Massachusetts Bay individuals, while

$33 \delta^{13} \mathrm{C}$, an indicator of marine vs. terrestrial foraging, was positively correlated with some

34 long-chain PFAS in CFRE chick livers. These results detail concentrations of legacy and

35 novel PFAS across different marine ecosystems along the US Atlantic East Coast.

36 There is also an indication that seabird phospholipid dynamics are negatively impacted

37 by PFAS, which should be further explored given the importance of lipids for seabirds. 
39 Per- and polyfluoroalkyl substances (PFAS) are anthropogenic organic contaminants used extensively in a variety of commercial, industrial, and military applications

41 globally. ${ }^{1}$ Continued, widespread use of PFAS with diverse formulae has resulted in the

42 detection of multiple PFAS into the global environment ${ }^{2-4}$. Industrial production has

43 shifted away from long-chain chemistries to replacements with fewer than seven

44 fluorinated carbons, polyfluorinated structures, and/or structurally modified iterations of

45 perfluoroalkyl acids (PFAAs) such as perfluoroalkyl ether acids (PFEAs) incorporating

46 different numbers of ether linkages ${ }^{5,6}$. PFEAs include both perfluoroalkyl ether

47 carboxylic acids (PFECAs) and perfluoroalkyl ether sulfonic acids (PFESAs).

Both legacy PFAS and new formulations may be released to the environment via both

50 direct or indirect discharges, or some interplay of the two ${ }^{1,7-9}$. The continued inputs of

51 PFAS act in tandem with their extreme environmental persistence to sustain the

52 proliferation of these compounds within terrestrial ${ }^{10}$, marine ${ }^{11}$, estuarine ${ }^{12}$, freshwater ${ }^{13}$,

53 cryosphere ${ }^{14}$, and atmospheric compartments ${ }^{14,15}$ worldwide. PFAS compounds can

54 permeate biota within these compartments, including marine invertebrates ${ }^{16}$, fish $^{17}$,

55 birds $^{18-21}$, and marine mammals ${ }^{22}$. This environmental and biological ubiquity presents

56 challenges for ecological health, as substantial evidence suggests a variety of legacy

57 and new PFAS have the potential for adverse effects across multiple taxa ${ }^{23,24}$.

59 Toxicology and field studies suggest associations between PFAS concentrations and 60 reproductive parameters, morphometric characteristics, and metabolic processes in 
61 avifauna ${ }^{25-31}$. Controlled studies across multiple taxa, including birds, also suggest

62 variable associations between PFAS and lipid production, metabolism, and storage

63 pathways ${ }^{32-34}$. Yet comprehensive assessments of PFAS exposure or potential toxicity

64 in wild avifauna are stymied by a lack of foundational data detailing the environmental

65 occurrence of diverse PFAS across multiple habitats and bird taxa. Transfer of PFAS

66 via trophic interactions is likewise still under investigation, with habitat- and food web-

67 specific trends apparent ${ }^{35-37}$. Furthermore, there is a dearth of data detailing PFAS

68 concentrations in avifauna near industrial point sources, or potential impacts related to

69 chronic, elevated exposure from such direct or substantial discharges ${ }^{29,30,38}$. This stands

70 as a significant data gap considering that effective protection of endangered species

71 and habitat surrounding contaminated sites relies on understanding exposure and

72 impacts in bird species and other keystone wildlife.

73

74 The oceans are thought to be the final sink for legacy and novel PFAS compounds,

75 receiving inputs via rivers/estuaries and atmospheric deposition². Long-lived seabirds

76 present an opportunity to assess and compare PFAS detection and trends across a

77 range of coastal and oceanic habitats. In their given marine habitats, seabirds act as

78 integrative sentinels due to their generally predictable life histories and foraging

79 strategies, long life span, top predator trophic position, sensitivity to environmental

80 stressors on observable time scales, and physiological interconnectivity to both air and

81 water $^{39,40}$. They assimilate resources and related environmental conditions, and

82 demonstrate organismal and population level responses. This responsiveness allows 
83 seabird population and individual condition to be utilized as indicators reflecting

84 chemical contamination and/or overall ecosystem health or stress ${ }^{20,41-43}$.

86 We used seabirds as sentinels to assess and contrast patterns and magnitude of PFAS

87 exposure in three marine regions. We targeted 36 PFAS in the livers of 31 juvenile

88 seabirds found dead in 2017 in three coastal and pelagic marine habitats with variable

89 PFAS exposure potential. The main objectives of this study were to a) measure and

90 compare legacy and emerging PFAS in different seabirds from marine habitats subject

91 to variable direct or indirect PFAS discharges, and b) ascertain any association between

92 stable isotope signatures approximating trophic habits, phospholipid levels, and PFAS

93 concentrations.

94

MATERIALS AND METHODS (1062 words)

96 Chemicals and Reagents

97 A total of 36 PFAS were assessed in juvenile seabird livers using target and suspect

98 screening, and 27 PFAS quantified (Table S1), including $\mathrm{C}_{4}-\mathrm{C}_{14}$

99 perfluorocarboxylates (PFCAs), $\mathrm{C}_{4}-\mathrm{C}_{10}$ perfluorosulfonates (PFSAs), three

100 perfluoroalkyl ether carboxylic acids (PFECAs), one perfluoroalkyl ether sulfonate

101 (PFESA), three fluorotelomer sulfonates (FTS), and three sulfonamide precursors

102 (Tables S1,S4-S5). More details about target and suspect analytes, chemicals, and

103 reagents can be found in the Supplementary Information (SI).

105 Sample Collection 
106 Liver tissue was obtained from six species of deceased juvenile seabirds. Juvenile

107 Great Shearwaters (Ardenna gravis) originated from Massachusetts Bay $(n=10)$ and

108 Herring Gull chicks (Larus argentatus smithsonianus) from Narragansett Bay $(n=10)$.

109 Royal Tern (Thalasseus maximus), Sandwich Tern (Thalasseus sandvicensis),

110 Laughing Gull (Leucophaeus atricilla), and Brown Pelican (Pelecanus occidentalis)

111 chicks originated from the Cape Fear River Estuary $(n=11)$ (CFRE) (Fig. S1). These

112 birds, while unique species with nuanced life histories and food web roles, reflect

113 broadly similar foraging preferences and strategies in coastal and pelagic habitats

114 (Table S2). Literature also implies similar PFAS bioaccumulative capacity between

115 different bird species, enabling a comparison of similar avifauna ${ }^{44-46}$.

117 The individuals analyzed here span several months in age, ranging from 2-4 week old

118 chicks to $\sim 6$ month old juveniles. Based on the long tissue half-life of PFAS, these

119 young birds predominantly reflect PFAS derived from maternal offloading, and thus the

120 highest internal concentrations experienced by each individual over their lifetime ${ }^{46-48}$.

121 More details supporting our use of a multi-species, variable age sample set can be

122 found in the SI.

123

124 The selected habitats represent a continuum of potential PFAS exposure, with the

125 highest likelihood of exposure in the CFRE downstream from a fluoropolymer

126 production facility. Narragansett Bay represents an intermediate potential for PFAS

127 exposure; it is a well-mixed coastal embayment adjacent to a large urban center, but

128 lacks major PFAS production facilities. The lowest likelihood of exposure, based on 
129 increased distance from direct human sources of PFAS, is reflected by seabird juveniles

130 collected from Massachusetts Bay. Massachusetts Bay is a productive offshore marine

131 habitat encompassing Stellwagen Bank National Marine Sanctuary, and representative

132 of the offshore pelagic environment of the North Atlantic (Fig. S1).

134 All individuals were necropsied in a standardized manner ${ }^{49}$. Liver tissue was used for 135 PFAS analysis and stable isotope analysis, while muscle was only used for stable 136 isotope analysis. Additional details about sample condition, sample procurement, and 137 individual sample details can be found in the SI.

139 Analysis of PFAS

140 Complete extraction methods are provided in the SI. Briefly, liver samples were

141 lyophilized and solvent-extracted in methanol using sonication, centrifugation, and 142 freezing, paired with graphitized non-porous carbon solid phase extraction.

143 Measurement and quantification of 25 PFAS was achieved using liquid chromatography

144 tandem-mass spectrometry (UPLC-MS/MS) experiments in negative electrospray

145 ionization mode. Further details about quantification and instrumental parameters are

146 provided in the SI. Estimates of PFAS concentrations were obtained by quantification

147 using isotope dilution. Method recovery ranged from $14-112 \%$ with a mean recovery of

$14862 \%$ across all compounds, similar to recoveries reported in other work using avian

$149 \operatorname{liver}^{47,50,51}$ (Table S6). 
151 Liver tissue was also assessed via suspect screening using high resolution mass

152 spectrometry (HRMS). Fresh tissue aliquots were extracted for PFEAs of interest by

153 means of protein precipitation and dilution ${ }^{19,52}$. Sample extracts were measured using a

154 ThermoFisher Orbitrap Fusion (Thermo Fisher Scientific, Waltham, MA, USA) operated

155 in heated electrospray ionization in negative mode as previously described ${ }^{19,52}$.

156

157 Concentrations of PFEAs were derived from these HRMS experiments. Nafion BP2 and

$158 \mathrm{PFO}_{5}$ DoDA were assessed using native standards and reported here quantitatively

159 while all other PFEAs were assessed based on previously determined accurate mass

160 and spectral information using a semi-quantitative approach (Tables S1, S5) ${ }^{8,53}$.

161 PFO 4 DA was the only PFEA detected in samples that lacked a native standard;

$162 \mathrm{PFO}_{4} \mathrm{DA}$ was reported as raw abundance and excluded from concentration calculations

163 due to the lack of an authentic native standard. Mass-labelled surrogates of similar

164 molecular weight and retention time were used in the absence of matched surrogates

165 for quantitation of Nafion BP2 and PFO 5 DoDA (Table S5).

166

167 For those compounds analyzed via both UPLC-MS/MS and HRMS, UPLC-MS/MS

168 concentrations are reported here due to more rigorous quality assurance and increased

169 sensitivity (Table S1). Further details about sample preparation, analysis, and quality

170 assurance for both UPLC-MS/MS and HRMS are provided in the SI.

171

172 Stable Isotope and Phospholipid Analysis 
173 Stable isotope analysis was used to evaluate trophic transfer of PFAS, as well as to

174 ensure trophic comparability of the sample set. $\delta^{15} \mathrm{~N}, \delta^{13} \mathrm{C}$, and $\delta^{34} S$ were measured in

175 muscle; $\delta^{15} \mathrm{~N}$ and $\delta^{13} \mathrm{C}$ were also measured in liver to facilitate comparison to a tissue

176 with a faster isotopic turnover rate ${ }^{42}$, given the unknown rate of PFAS turnover in avian

177 tissues.

178

179 Total lipid was extracted from liver tissue aliquots using a modified Folch method, and

180 phospholipid content of liver tissue assessed colorimetrically using an EnzyChrom

181 Phospholipid Assay Kit (BioAssay Systems, Hayward, CA) ${ }^{54}$. More details about stable

182 isotope and phospholipid analysis are available in the SI.

183

184 Statistical Analysis

185 All data manipulation and statistical analyses were performed in $R$ version 3.6.1 ( $R$ Core

186 Team, 2020) ${ }^{55}$. Concentrations were converted to a wet weight basis for comparability

187 to other literature values. Responses not detected or below the linear dynamic range of

188 the curve were labeled as "nd" and assigned a value of zero. Observations below

189 method reporting limits with a detection frequency higher than $50 \%$ were replaced with

190 the half the method reporting limit for statistical analyses, and included as such in

191 calculation of summed concentrations ( $\left.\sum{ }_{19} P F A S\right)$ and statistical analysis ${ }^{56}$. Data were

192 checked for normality and homoscedasticity using the Shapiro-Wilk test and Levene's

193 test. Concentration data were non-normal despite log transformation and therefore

194 treated non-parametrically for statistical analyses; habitat groups displayed no

195 significant differences in variance. Differences between habitats were assessed using 
196 Kruskal-Wallis tests with post hoc application of Dunn's test with Bonferroni correction

197 for multiple testing, or with the Wilcoxon rank sum test. Relationships between

198 concentrations were assessed using Spearman rank correlation coefficients $\left(R_{s}{ }^{2}\right) \cdot R_{s}{ }^{2}$

199 presents the proportion of the rank variance explained by the correlation between

200 variables with test assumptions more suitable for this dataset, providing insight about

201 the relationship similar to the Pearson $R^{2}$. Liver-water bioaccumulation factors (BAFs)

202 were calculated by dividing geometric mean liver PFAS levels by measured or

203 estimated surface water concentrations adjacent to nesting or collection locations,

204 followed by log transformation; more details about BAF calculations can be found in the 205 SI.

206

207 RESULTS AND DISCUSSION (3112 words, 2100 word equivalents for 1 table +4 208 figures)

209 Observed detection frequencies and patterns by habitat

210 Samples were screened for 36 analytes using target and suspect screening; 27

211 analytes were quantified using native standards. Only one semi-quantitative compound

212 was detected via suspect screening, $\mathrm{PFO}_{4} \mathrm{DA}$. 19 of the 27 quantifiable analytes were

213 measured above detection limits in at least one sample, and detection frequencies

214 varied by habitat. PFOS, PFNA, PFDA, and PFUnDA were present in at least $97 \%$ of 215 individuals (Table 1). 


\begin{tabular}{|c|c|c|c|c|c|c|}
\hline \multicolumn{7}{|c|}{ \% Detection by Ecosystem } \\
\hline Compound & Family & $\begin{array}{c}\# \text { Fluorinated } \\
\text { Carbons }\end{array}$ & $\begin{array}{l}\text { Mass. } \\
\text { Bay }\end{array}$ & $\begin{array}{l}\text { Narra. } \\
\text { Bay }\end{array}$ & CFRE & All \\
\hline N-MeFOSAA & FASAA & 8 & 0 & 0 & 0 & 0 \\
\hline $\mathrm{N}$ - EtFOSAA & FASAA & 8 & 0 & 0 & 0 & 0 \\
\hline $\mathrm{FOSA}^{\mathrm{a}}$ & FASA & 8 & 0 & 0 & 27 & 10 \\
\hline $4: 2$ FTS & FTS & 4 & 0 & 0 & 0 & 0 \\
\hline $6: 2$ FTS & FTS & 6 & 0 & 0 & 0 & 0 \\
\hline $8: 2$ FTS & FTS & 8 & 0 & 0 & 0 & 0 \\
\hline PFBA & PFCA & 3 & 100 & 80 & 73 & 84 \\
\hline PFPeA & PFCA & 4 & 0 & 0 & 0 & 0 \\
\hline PFHxA & PFCA & 5 & 0 & 30 & 27 & 19 \\
\hline PFHpA & PFCA & 6 & 0 & 0 & 0 & 0 \\
\hline PFOA & PFCA & 7 & 0 & 0 & 64 & 23 \\
\hline PFNA & PFCA & 8 & 100 & 100 & 100 & 100 \\
\hline PFDA & PFCA & 9 & 90 & 100 & 100 & 97 \\
\hline PFUnDA & PFCA & 10 & 100 & 90 & 100 & 97 \\
\hline PFDoA & PFCA & 11 & 0 & 10 & 27 & 13 \\
\hline PFTrDA & PFCA & 12 & 70 & 20 & 27 & 39 \\
\hline PFTeDA & PFCA & 13 & 0 & 10 & 0 & 3 \\
\hline PMPA & PFECA & 3 & 0 & 0 & 0 & 0 \\
\hline $\mathrm{PFO}_{2} \mathrm{HxA}$ & PFECA & 3 & 0 & 0 & 0 & 0 \\
\hline PEPA & PFECA & 4 & 0 & 0 & 0 & 0 \\
\hline $\mathrm{PFO}_{3} \mathrm{OA}$ & PFECA & 4 & 0 & 0 & 0 & 0 \\
\hline HFPO-DA & PFECA & 5 & 0 & 0 & 9 & 3 \\
\hline $\mathrm{PFO}_{4} \mathrm{DA}^{\mathrm{b}}$ & PFECA & 5 & 0 & 0 & 70 & 23 \\
\hline $\mathrm{PFO}_{5} \mathrm{DoDA}$ & PFECA & 6 & 0 & 0 & 100 & 36 \\
\hline Nafion BP4 & PFESA & 6 & 0 & 0 & 0 & 0 \\
\hline \begin{tabular}{|l|} 
Nafion BP2 \\
\end{tabular} & PFESA & 7 & 20 & 10 & 100 & 45 \\
\hline Nafion BP1 & PFESA & 7 & 0 & 0 & 0 & 0 \\
\hline NVHOS & PFESA & 4 & 0 & 0 & 0 & 0 \\
\hline PFBS & PFSA & 4 & 0 & 10 & 0 & 3 \\
\hline PFPeS & PFSA & 5 & 20 & 0 & 0 & 7 \\
\hline PFHxS & PFSA & 6 & 10 & 10 & 55 & 26 \\
\hline PFHpS & PFSA & 7 & 0 & 0 & 55 & 19 \\
\hline PFOS & PFSA & 8 & 100 & 100 & 100 & 100 \\
\hline PFNS & PFSA & 9 & 0 & 0 & 0 & 0 \\
\hline PFDS & PFSA & 10 & 0 & 10 & 9 & 7 \\
\hline PFECHS & $\begin{array}{l}\text { Cyclic } \\
\text { PFSA }\end{array}$ & 8 & 0 & 0 & 0 & 0 \\
\hline
\end{tabular}

218 Table 1. Detection frequency of quantifiable and semi-quantitative analytes in seabird

219 juveniles from each habitat and as a total sample set across all habitats combined.

220 Mass. Bay $=$ Massachusetts Bay, Narra. Bay $=$ Narragansett Bay, and CFRE $=$ Cape

221 Fear River Estuary. Family names are from Buck et al. 2011. Compounds highlighted in

222 gray are those compounds detected above reporting levels in at least $97 \%$ of individuals 
223 via LC-MS/MS. ${ }^{a}$ Detection based on raw abundances in comparison to blank raw

224 abundances due to lack of authentic standards. ${ }^{b}$ Low recovery (14\%) related to sample 225 preparation (Large table, 600 word equivalent)

226

227 The highest $\sum{ }_{19}$ PFAS measured was $390 \mathrm{ng} / \mathrm{g}$ w.w. liver comprised of 14 quantifiable 228 analytes, found in a CFRE Royal Tern chick. The lowest $\sum{ }_{19} P F A S$ concentration was 229 observed in a juvenile Great Shearwater from Massachusetts Bay containing $\sum{ }_{19} P F A S$ 230 of $26 \mathrm{ng} / \mathrm{g}$, comprised of 5 analytes above detection limits (Fig. 1). Chicks from the 231 CFRE system contained significantly greater concentrations and number of PFAS than 232 juveniles from Massachusetts Bay or Narragansett Bay (Dunn's test; $p<0.001$ ) (Figs. 233 1a, 3a). There was no significant difference between mean $\sum$ 19PFAS levels observed in 234 individuals from Narragansett Bay and Massachusetts Bay (Fig. 3a), though Great 235 Shearwater individuals were older than Narragansett Bay chicks, and may 236 underestimate levels found in chicks of this species. Within each habitat, concentrations 237 were not significantly different between male and female chicks, though the sample size 238 of sexed individuals was small (Table S17). 


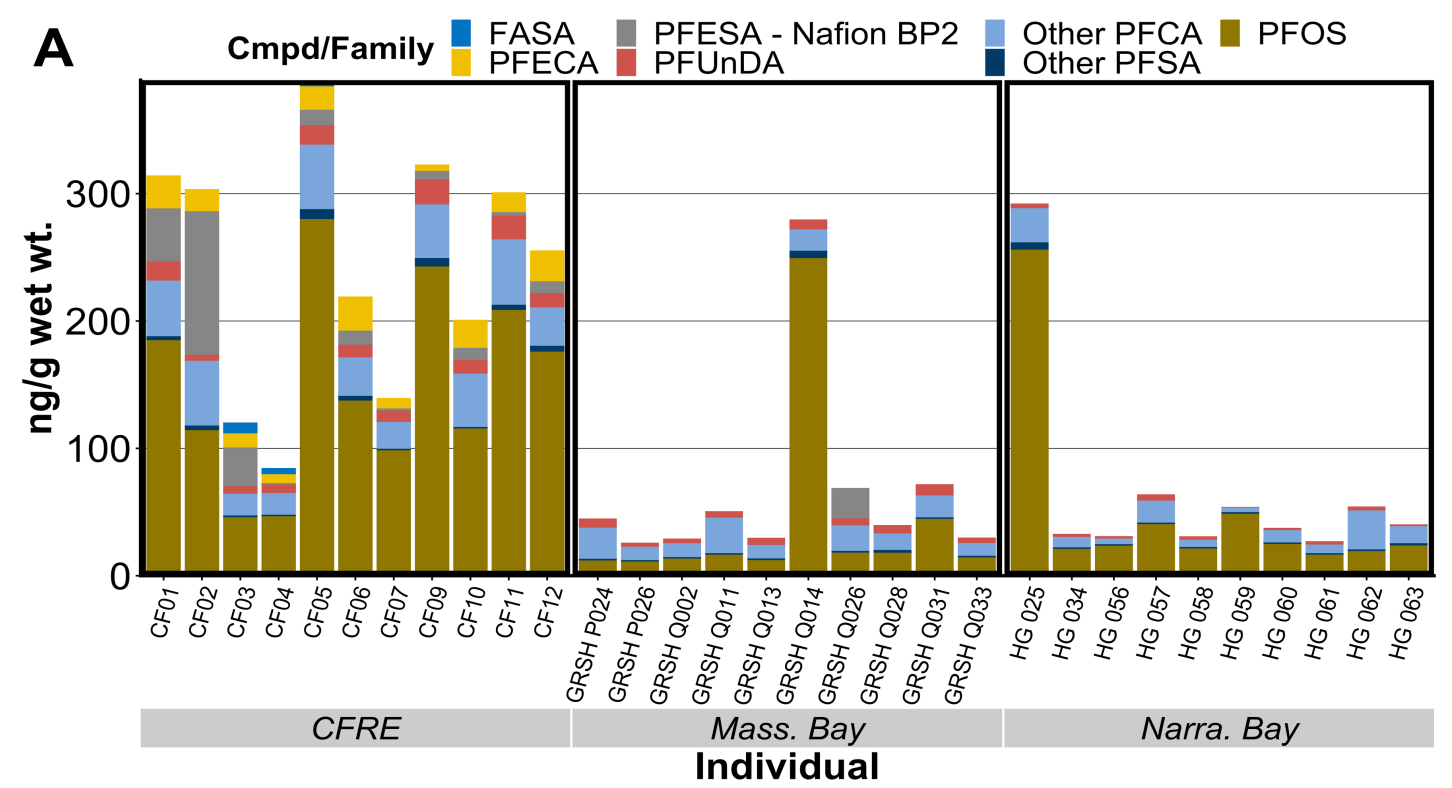

B Compound $\square$ Nafion BP2 $\square$ PFO5DoDA $\square$ Nafion BP2 - below LDR

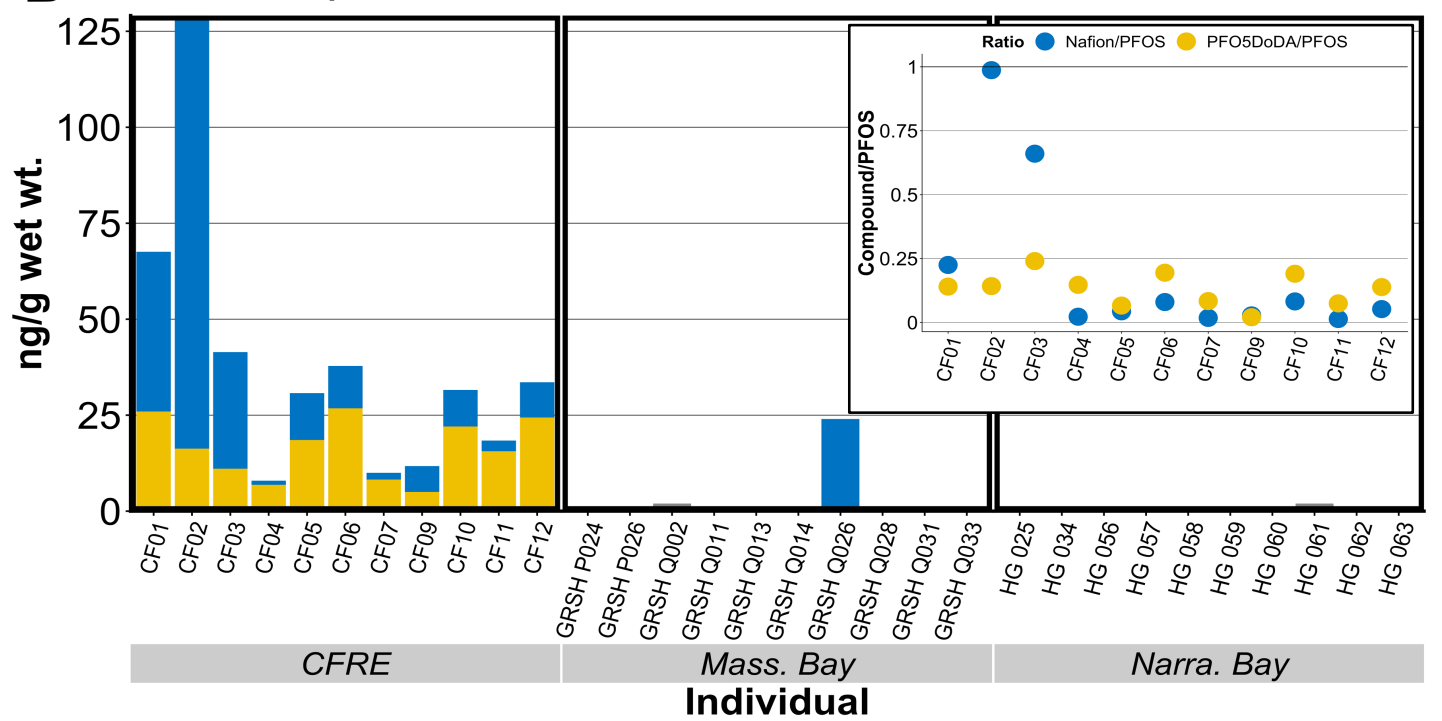

Individual

Figure 1. Measured concentrations of A) PFAS in juvenile seabird livers measured via

242 LC-MS/MS, B) two emerging PFAS measured via targeted HRMS, alongside B-inset)

243 ratios of emerging PFEAs to PFOS in CFRE chicks. Nafion BP2 concentrations

244 positively identified in non-CFRE chicks but below the linear dynamic curve range are

245 graphed in panel B as half the reporting limit; grey arrows are used to distinguish these 246 data points. (Large figure, 600 word equivalent) 
248 Multiple PFEAs were not detected, including novel PFECAs PMPA, PEPA, PFO ${ }_{2} \mathrm{HxA}$, 249 and $\mathrm{PFO}_{3} \mathrm{OA}$, and novel PFESAs NVHOS, Nafion byproduct 4 and 1. No fluorotelomer 250 sulfonates were detected above reporting limits, nor N-EtFOSAA or N-MeFOSAA. The

251 lack of bioaccumulation of shorter-chain PFEAs may be analogous to the reduced

252 bioaccumulation potential of short-chain PFCAs in upper trophic level homeotherms ${ }^{57}$.

253 The lack of detection of these compounds may also denote in vivo biotransformation.

254 Research in other biota has shown fluorotelomer sulfonates are precursors to some 255 PFCAs ${ }^{58}$ while N-EtFOSAA and N-MeFOSAA are PFOS precursors ${ }^{7}$. Further work is 256 required to deduce if the non-detects observed in this study are indicative of reduced 257 bioavailability, rapid biotransformation, or the true absence of a compound in these 258 environments and food webs. FOSA, a perfluoroalkane sulfonamide, was only 259 detectable in three birds from the CFRE. These detections may be the result of 260 continuous, high levels of FOSA or FOSA-precursors related to production activities or

261 legacy PFAS sources in the region ${ }^{53}$. Such continuous inputs could exceed metabolic 262 capacity and cause tissue residues of FOSA.

264 Continued dominance of PFOS in juvenile seabirds

265 PFOS was the most abundant compound in all sampled livers, making up 58\% of total 266 liver concentrations across the sample set. The proportion of PFOS measured in each 267 individual varied by habitat, with the CFRE and Narragansett Bay individuals containing 268 the highest geometric mean of $61 \%$ and $67 \%$ PFOS, respectively (Fig. 2). 


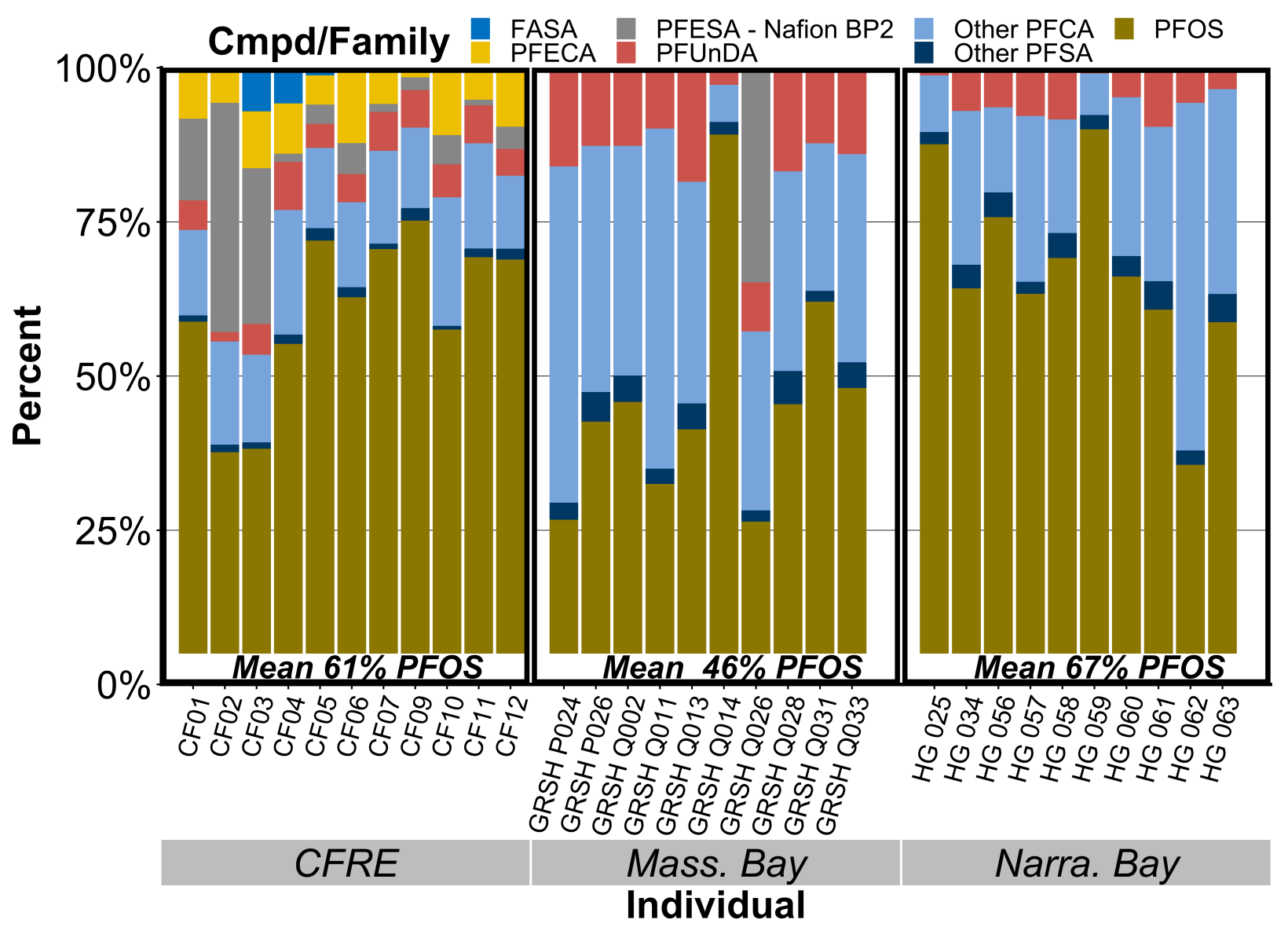

270 Figure 2. The composition of PFAS in liver tissue, presented by individual and grouped

271 by habitat.

273 These data align well with previous literature that determined a high proportion of PFOS

274 in seabird livers, eggs, and serum in species from multiple ecological provinces ${ }^{20,21,59-63}$.

275 The highest PFOS concentration measured in this study was $280 \mathrm{ng} / \mathrm{g}$ w.w. liver in a

276 Sandwich Tern chick from the CFRE, similar or higher than levels measured within the

277 past ten years in other long-lived temperate seabirds ${ }^{20,21,60,61}$. Average avian toxicity

278 reference values (TRVs) for PFOS reported by Newsted et al. of $600 \mathrm{ng}$ PFOS/g liver

279 were approximately 2-30 times higher than PFOS levels reported in these young birds ${ }^{64}$.

280 Seven of eleven CFRE chicks exceeded the female-specific liver TRV of $140 \mathrm{ng}$ 
281 PFOS/g liver; these birds were female or not yet able to be sexed visually ${ }^{64}$. One female

282 from Mass. Bay and one unsexed bird from Narra. Bay also exceeded the female283 specific TRV.

285 Our data indicate the continued occurrence of PFOS in juvenile avifauna at levels of 286 toxicological concern despite a production phase-out of perfluorooctanesulfonyl fluoride 287 (POSF), PFOS, and PFOS precursors in the US in the early $2000 \mathrm{~s}^{1}$. The phase-out in 288 2000-2002 resulted in decreased PFOS and/or precursor concentrations in select 289 environmental matrices ${ }^{22,65}$. Modeling and empirical results suggest decreased 290 availability of volatile precursor compounds like FOSA, whose environmental 291 occurrence responded quickly to the phase-out, likely caused any decreasing trends of 292 PFOS in wildlife observed after $2002^{22}$. Yet biotic trends in PFOS vary based on spatial 293 habits, proximity to local sources, and with trophic strategy, and there is no consistent 294 global pattern of continually decreasing PFOS across multiple avian matrices ${ }^{18,60,63,66}$. 295 Current PFOS concentrations in wildlife reflect exposure to extant precursor compounds 296 that may transform in situ or in vivo to PFOS, in vivo depuration of PFOS, and sustained

297 transfer of PFOS itself via environmental or trophic interactions ${ }^{65,67,68}$. Our results 298 highlight the continued biological occurrence of PFOS as a function of these exposures.

300 Variable contribution of PFCAs by Habitat

301 Concentrations of PFCAs including PFDA, PFNA, and PFUnDA reported in this study 302 were similar to or elevated compared to concentrations previously reported in temperate 303 species, as well as in birds from Great Lakes and Arctic environments $4,60-62,66,69$. In 
304 CFRE, mean concentrations of PFCAs increased up to PFDA, where PFOA $<$ PFNA $<$

305 PFDA > PFUnDA, whereas in Massachusetts Bay PFNA < PFDA < PFUnDA and in

306 Narragansett Bay PFNA < PFDA $\approx$ PFUnDA.

307

308 The proportion of $\sum$ PFCAs to $\sum$ PFSAs varied between habitats, with individuals from

309 CFRE and Narragansett Bay dominated by PFSAs while individuals from

310 Massachusetts Bay contained a significantly higher proportion of PFCAs (Dunn's test; $p$

$311<0.001)$ (Fig. 3b). The dominance of PFCAs in offshore Massachusetts Bay individuals

312 was driven partly by significantly higher concentrations of the $C_{11}$ PFCA, PFUnDA, in

313 offshore individuals (Dunn's test; $p<0.05$ ) (Fig. S2). Mean concentrations of other long-

314 chain $\left(\mathrm{C}_{n} \mathrm{~F}_{2 n-1} \mathrm{COOH}, \mathrm{n} \geq 7\right)$ PFCAs found in both Narragansett Bay and Massachusetts

315 Bay were not significantly different.

316

317 

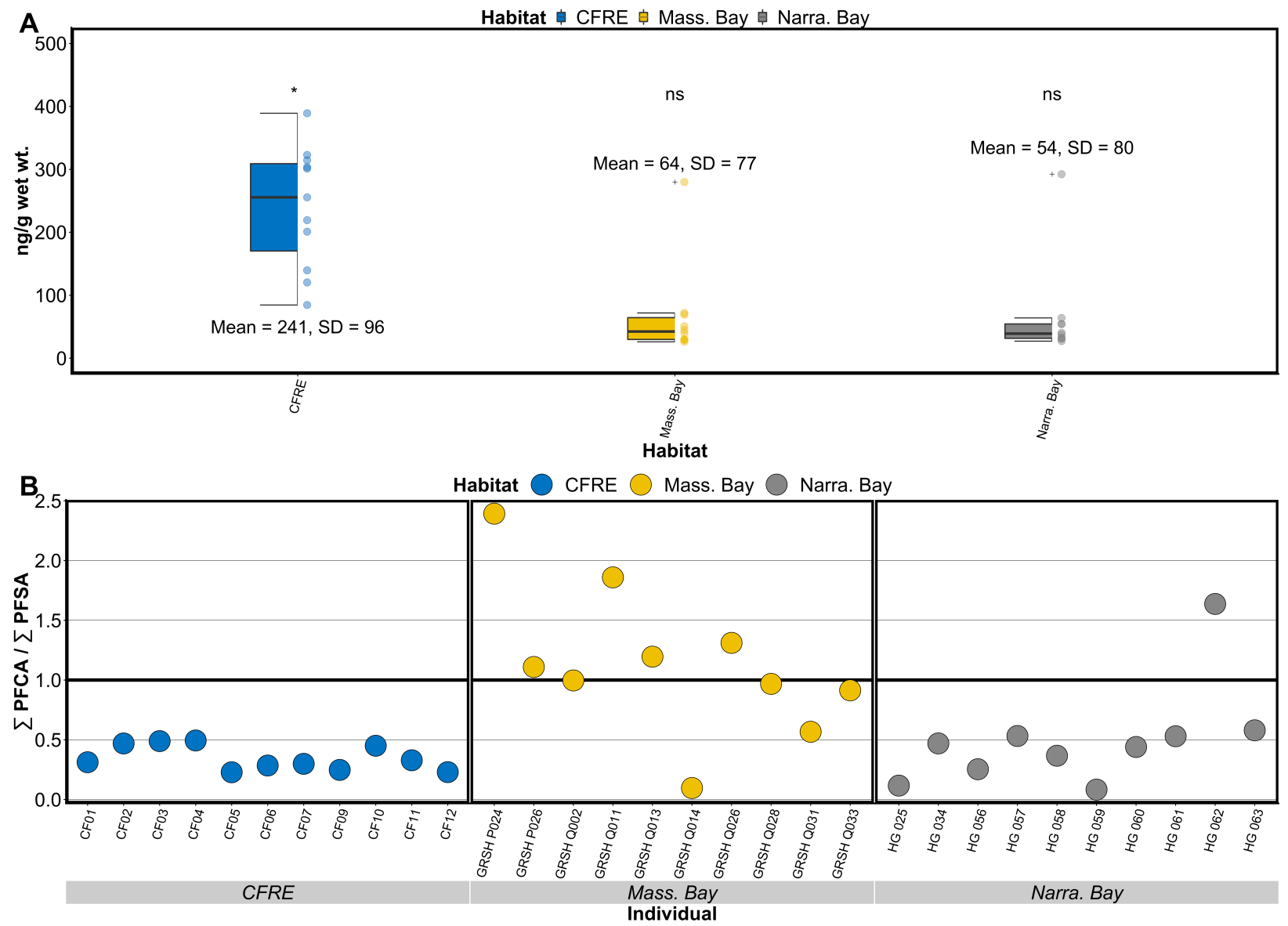

319 Figure 3. $\sum{ }_{19}$ PFAS presented in A) as a boxplot, with the dark line representing the

320 median, box limits representing the first and third quartiles, whiskers denoting 1.5 times

321 the interquartile range, and crosses denoting outliers. The asterisk indicates a

322 statistically significant difference between habitat mean $\sum$ 19PFAS compared via

323 Wilcoxon rank sum test using the CFRE as the reference group, while B) presents ratios

324 of $\sum$ PFCAs to $\sum$ PFSAs in each individual. Ratios above 1 indicate PFCA dominance,

325 while ratios below 1 indicate PFSA dominance. (Small figure, 300 word equivalent)

326

327 The preferential dominance of PFUnDA seen here in seabirds from offshore

328 Massachusetts Bay habitat has been observed in Arctic marine mammals as well as

329 Arctic and temperate seabirds $4,20,21,70$. These studies exemplify a broader pattern in 
330 which PFCAs with odd chain lengths are more abundant in biota than PFCAs with even

331 chain lengths. This pattern is a result of preferential bioaccumulation of longer-chain

332 homologues, coupled to substantial atmospheric and water-borne transport of PFCAs

333 and PFCA precursors of variable chain length ${ }^{15,23,70-72}$. Notably, our data suggests this

334 pattern only applies to biota exposed to diffuse PFAS sources, as CFRE birds subject to

335 localized point sources of PFAS actually contained greater concentrations of PFDA

$336\left(\mathrm{C}_{10}\right)$ compared to PFUnDA $\left(\mathrm{C}_{11}\right)$.

338 Limited data suggest environmentally relevant exposures of long-chain PFCAs are

339 associated with changes in metabolic rate, oxidative stress, and reproductive behaviors

340 in Arctic black-legged kittiwakes ${ }^{25,73}$. We highlight the need for further research about

341 the formation, long-range transport, occurrence, and effects of PFUnDA and other long-

342 chain PFCAs in marine systems supporting seabirds. Such a comprehensive

343 understanding is necessary given the sustained or increasing occurrence of long-chain

344 PFCAs in remote wildlife ${ }^{21,63}$, the substantial suite of stressors currently impacting

345 marine species globally, and the continued importance of marine food resources to

346 human communities ${ }^{74}$.

348 Potentially Confounding Factors

349 The opportunistic sample set of dead chicks and juveniles enabled us to measure PFAS 350 in liver tissue, allowed the acquisition of unique samples from the CFRE before the 351 cessation of certain industrial PFAS discharges, and allowed assessment of PFAS 352 during a critical development window in immature individuals from data-deficient 
353 habitats. Yet this opportunistic sampling also introduced potentially confounding factors

354 related to the variable species and ages of collected individuals.

356 The older Great Shearwater juveniles in this study were self-feeding for approximately

357 two months, while the chicks from other habitats were still being provisioned by their

358 parents. Great Shearwater PFAS profiles may therefore reflect increased input from

359 dietary sources. Immature Shearwaters are thought to eat similar items as adult Great

360 Shearwaters ${ }^{75}$; hence - the PFAS profile should be conserved, allowing their

361 comparison between habitats. More likely, the older juveniles reflect growth dilution, and

362 may underestimate PFAS concentrations present in chicks of this species.

363

364 Literature to date has yet to identify significant differences between uptake, metabolism,

365 or elimination pathways and rates between similar bird species ${ }^{20,44-46}$; bioaccumulation

366 in birds appears driven by habitat and trophic exposures. However, species-specific

367 toxicokinetics have been identified between multiple mammal species ${ }^{76}$. We also have

368 not investigated the possibility of developmental changes in molecular receptors of

369 PFAS in birds or other wildlife, although PFAS have been found at higher levels in 370 juveniles than adults across multiple taxa ${ }^{48,77,78}$. We suggest additional research on the

371 toxicokinetic behavior of PFAS in different bird species and across developmental

372 stages, given their utility and importance as sentinel predators.

373

374 Association with phospholipid content 
375 Lipid moieties play key roles in organismal metabolism, reproduction, migration, and

376 other basic functions key to wildlife health and fitness. Phospholipid levels were

377 significantly $(p<0.05)$ associated with PFOS in Massachusetts Bay and CFRE

378 individuals $\left(R_{s}{ }^{2}=0.52\right.$ and 0.45 , respectively) (Fig. 4a). $\sum_{19} P F A S$ was more weakly

379 associated with measured phospholipids $\left(\mathrm{R}_{\mathrm{s}}{ }^{2}=0.14\right.$ and 0.45 for Massachusetts Bay

380 and CFRE individuals, respectively and $R_{s}{ }^{2}=0.51$ when assessed as a total sample

381 set, $n=31$ ). There was also a statistically significant correlation between PFNA and

382 phospholipid in CFRE chicks $\left(R_{s}^{2}=0.53, p<0.05\right)$.
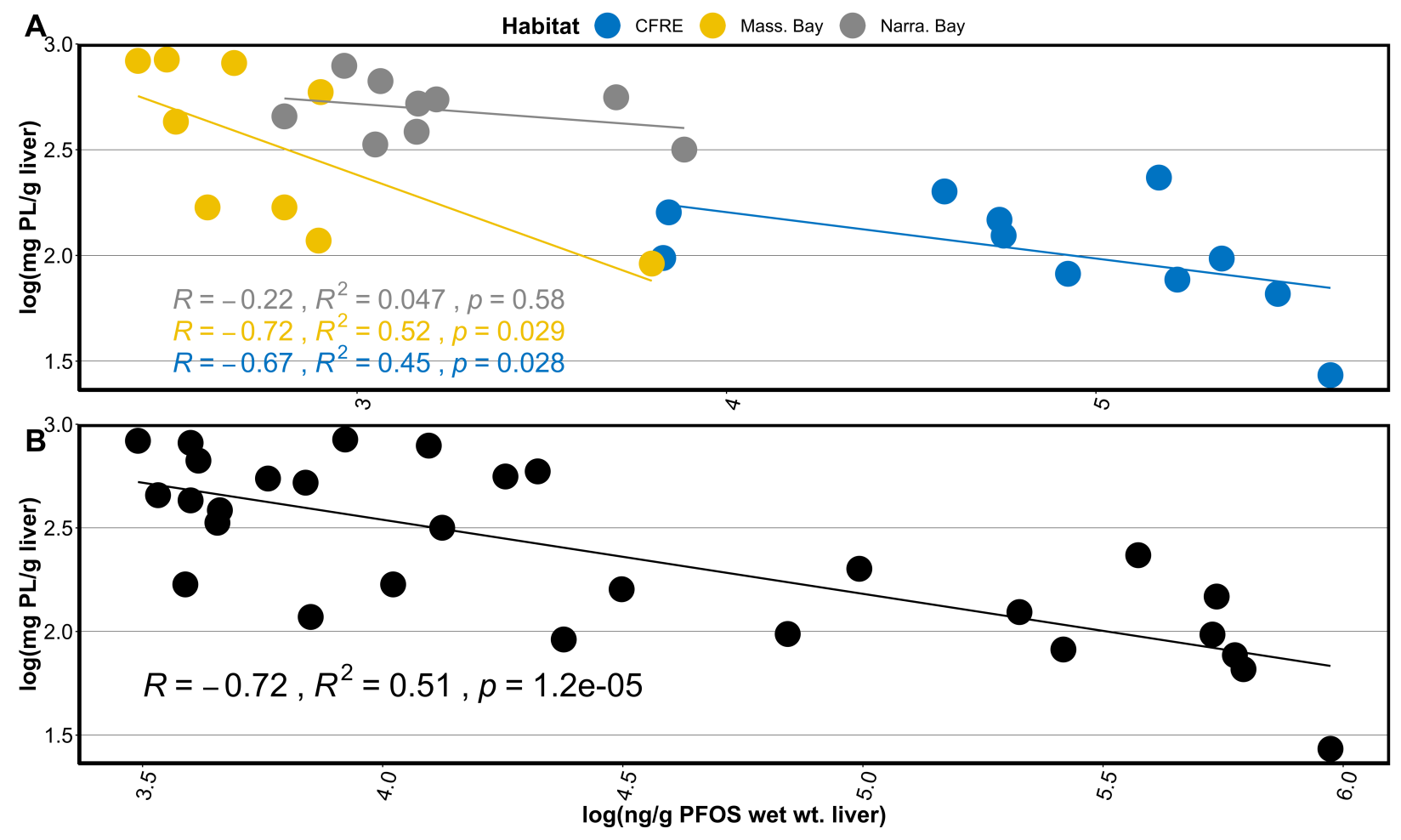

385 Figure 4. A) presents log-transformed concentrations of PFOS vs phospholipid (PL) 386 grouped by habitat, while B) displays log-transformed PFOS and phospholipid (PL), 387 assessed as a total sample set $(n=31)$. Text annotation presents $R, R_{s}{ }^{2}$, and $p$-value 388 derived from Spearman rank correlation analysis. (Small figure, 300 word equivalent) 
390 The importance of phospholipids in the accumulation of long-chain PFAAs has been 391 supported by both empirical observations from marine mammals as well as modeling 392 results $54,79-81$. Conversely, controlled studies in chickens suggest PFOS may impact 393 lipid metabolism and production via gene suppression, suggesting PFOS may instead 394 indirectly mediate lipid levels $32,33,68,82$. Currently, our understanding of phospholipid395 PFAS associations and relationships lacks substantial field-derived data beyond marine 396 mammals.

398 These data, though derived from a small sample set, suggest an association between 399 environmentally relevant concentrations of PFOS (and possibly PFNA) and decreased 400 liver phospholipid content in wild seabirds, a previously unreported phenomenon (Fig. 401 4). Lipid levels in seabird livers may be influenced by a variety of physiological and 402 nutritional constraints not measured within the scope of this study; we note the lack of 403 comparative baseline data describing liver phospholipid levels in the species examined 404 within this work as a possible limiting factor. However, lines of evidence from multiple 405 disciplines suggest a high conservation of non-diet lipid composition in a given tissue 406 between similar avian species ${ }^{83-86}$. Controlled animal studies also point to the same 407 relationship between PFOS exposure and changes in phospholipid content, lipid 408 profiles, and lipid metabolism alongside altered expression of genes related to lipid 409 dynamics in the livers of domestic chickens ${ }^{32,33,68,82}$. Most relevant to the results seen 410 here, subcutaneous delivery of $0.02 \mathrm{mg} / \mathrm{ml}$ and $0.1 \mathrm{mg} / \mathrm{ml}$ PFOS resulted in decreased 
411 phospholipid content in domestic chicken plasma after 28 days of exposure and 28 days

412 of depuration ${ }^{68}$.

413 Laboratory-based studies using model phospholipid bilayers, liposomes, and bacterial

414 membranes exhibit an inverse relationship between PFAS levels and phospholipids,

415 manifested via increased incorporation of PFAS into bilayers and subsequently

416 decreased lipid content. These studies also found increased bilayer disruption by PFAS

417 based on chain-length and functional group ${ }^{87,88}$. The results from these controlled

418 membrane studies are not easily translated to realistic biological conditions, yet in

419 combination with other evidence (our data, previous work in pilot whales ${ }^{54}$, and

420 controlled animal studies referenced above) we highlight a potential and currently

421 undefined relationship between PFOS and phospholipid responses in wild organismal

422 systems at environmentally relevant exposure levels. Further research is warranted to

423 better describe relationships between PFAS-driven lipid responses in combination with

424 the role of lipids in PFAS partitioning.

425

426 Relationship to stable isotope data

$427 \quad \delta^{15} \mathrm{~N}$ is frequently used as a proxy for trophic level across terrestrial and aquatic

428 systems; while system and prey-base specific, enrichment of $\delta^{15} \mathrm{~N}$ typically indicates

429 foraging at a higher trophic level${ }^{42}$. Legacy persistent organic pollutants (POPs) like

430 polychlorinated biphenyls or DDT frequently increase in concentration with trophic level

431 as approximated by $\delta^{15} \mathrm{~N}$ values, due to bioaccumulation of hydrophobic POPs in lipid-

432 rich consumer matrices ${ }^{89}$. Here, we found $\delta^{15} \mathrm{~N}$ values and calculated trophic level were

433 not significantly associated with concentrations of the majority of individual PFAS in 
434 each habitat (Fig. S6, Table S23). PFOS and $\sum_{19}$ PFAS were positively associated with

$435 \delta^{15} \mathrm{~N}$ only in Massachusetts Bay individuals (Table S23).

436

$437 \quad \delta^{13} \mathrm{C}$ values reflect basal sources of primary production supporting trophic networks ${ }^{42}$

438 and exhibit significantly less step-wise change with prey-consumer interactions. This

439 allows bulk differentiation between inshore and offshore food chains based on

440 characteristic enrichment or depletion of $\delta^{13} \mathrm{C}$ associated with terrestrial vs marine

441 primary production (Fig. S8) ${ }^{42} . \delta^{13} \mathrm{C}$ ranged from -19.8 to -17.0 in CFRE individuals,

442 and from -22.5 to -19.0 in Narragansett and Massachusetts Bay individuals. In contrast

443 to previous studies, concentrations of $\mathrm{C}_{9}, \mathrm{C}_{10}, \mathrm{C}_{11}$, and $\mathrm{C}_{13}$ PFCAs, PFOS, and $\sum_{19} \mathrm{PFAS}$

444 in CFRE birds were associated with enriched $\delta^{13} \mathrm{C}$ values in seabird muscle and liver,

445 likely reflecting the unique geomorphology of the CFRE system and energy-saving

446 coastal foraging habits of CFRE seabird species (Fig. S7). PFTrDA and PFDA were

447 negatively associated with $\delta^{13} \mathrm{C}$ values in Mass. Bay individuals, which may reflect

448 increased exposure to long-chain PFCAs in offshore environments via long-range

449 transport and transformation of PFCA precursors. More details about relationships

450 between PFAS and stable isotopes are available in the SI.

451

452 Unique occurrence of emerging compounds

453 HRMS analysis helped us confirm the presence of (previously identified) PFEAs in chick

454 livers for the first time: Nafion BP2 and $\mathrm{PFO}_{5}$ DoDA were found in livers of all CFRE

455 individuals $(n=11)$ while PFO ${ }_{4}$ DA was found in 7 of 11 CFRE individuals (Fig. 1 b, Table 456 S16). 
458 The maximum Nafion BP2 concentration was $110 \mathrm{ng} / \mathrm{g}$ w.w. in a Laughing Gull chick 459 and a maximum $\mathrm{PFO}_{5}$ DoDA concentration of $30 \mathrm{ng} / \mathrm{g}$ w.w. in a Royal Tern chick (Fig.

460 1b). Nafion BP2 was also detected in two Great Shearwaters and one Herring Gull from 461 outside the CFRE, or $15 \%$ of the non-CFRE sample set (Figs. 1b, S10).

463 The detection of these PFEAs in CFRE chicks is due to proximity to an industrial point 464 source and the then-ongoing discharge of PFEAs to surface water. CFRE chicks were 465 hatched in a well-mixed estuary $\sim 145 \mathrm{~km}$ downstream from a fluoropolymer production 466 facility in Fayetteville, NC. "Gen X" or HFPO-DA, along with other PFEAs were detected 467 at high levels in Cape Fear River surface water and Wilmington, NC drinking water as a 468 result of industrial wastewater discharges into the mainstem Cape Fear River ${ }^{53,90,91 .}$ 469 Increased research attention following the 2017 termination of the industrial discharge 470 has revealed the presence of multiple PFEAs in downstream environments, fish, and 471 humans ${ }^{52,92}$.

472 Notably, concentrations of Nafion $\mathrm{BP} 2, \mathrm{PFO}_{5} \mathrm{DoDA}$, and $\mathrm{PFO}_{4} \mathrm{DA}$ reported here are the

473 highest biotic measurements of these PFEAs at the greatest distance from the 474 production plant recorded to date, similar to measured PFOS concentrations and PFOS 475 bioaccumulation factors in chick livers (Figs. 1, S9). Average PFEA concentrations 476 reported here from seabird chick liver tissue (ppb, ng/g) are approximately 20 times 477 higher than PFEA concentrations found in striped bass serum (ppb, $\mathrm{ng} / \mathrm{mL})^{52}$. 
479 Observed PFEA concentrations in CFRE chicks are likely not a result of riverine 480 foraging proximate to the plant discharge or incorporation of freshwater prey items by

481 seabird parents. The species sampled in this study are strictly marine, and do not

482 inhabit or use freshwater, riverine habitats based on colony observations and their

483 foraging preferences (marine and estuarine prey including forage fish, squid, and

484 crustaceans $)^{93-95}$. PFEAs were previously measured in river water upstream from the

485 breeding colony at very high concentrations while the industrial discharge was

486 ongoing ${ }^{90,96}$. Their detection in seabirds here suggests these emerging PFEAs are

487 environmentally persistent and capable of significant downstream transport and biotic

488 uptake via undefined water-borne, particulate, and/or atmospheric pathways.

489

490 The confirmed presence of Nafion BP2 in three individuals outside of the CFRE is the

491 first identification of Nafion BP2 in biota outside of the CFRE region, reiterating the

492 environmental persistence and mobility of Nafion BP2. These detections are difficult to

493 explain because virtually no data exists describing Nafion BP2 environmental

494 occurrence beyond the CFRE region. Nafion BP2 detections in non-CFRE chicks may

495 be due to migratory proximity to the CFRE; we consider this unlikely due to the lack of

496 evidence indicating use or reliance on the CFRE system by non-CFRE populations

497 sampled in this study.

498

499 More likely, Great Shearwater juveniles and Herring Gull chicks accumulated Nafion

500 BP2 as a result of exposure to indirect discharges contaminated with Nafion products or

501 related degradation byproducts. Nafion is the brand name of a perfluorinated ionic 
502 polymer first discovered in the 1960 s via modification of the Teflon polymer. The

503 Fayetteville, NC production facility has produced this ionic polymer since the 1980 s.

504 Nafion byproduct-2 is a side product from the reaction of the polymer precursors..$^{92}$.

505 Little data exist describing how production, use, or disposal of this perfluorinated

506 polymer may contribute to PFAS to the environment. Evidence from the CFRE suggests

507 Nafion production waste streams may contribute substantial loads of Nafion byproducts

508 to receiving environments ${ }^{52,53,90,92}$. Feng et al. (2015) investigated the thermolysis

509 products of Nafion 117, a typical Nafion membrane and suggested high-temperature

510 uses or disposal of Nafion via incineration may produce multiple perfluorinated

511 structures as a result of incomplete combustion ${ }^{97}$; Nine groups of fluorinated analogues

512 were identified as a result of thermal treatment of Nafion 117 membranes, including

513 breakdown products structurally similar to Nafion BP2 ${ }^{97}$. Additional research documents

514 chemical and mechanical degradation pathways relevant to Nafion membrane function

515 and efficiency ${ }^{98}$. The (albeit limited) detection of Nafion BP2 beyond CFRE individuals

516 warrants additional screening of Nafion byproducts in diverse environmental matrices,

517 investigation into the life-cycle of Nafion technologies, and potential environmental

518 persistence of PFESAs.

519

520 Divergent sources of emerging and legacy PFAS in the CFRE system

521 Ratios of PFEAs to PFOS varied between individuals, with PFEA levels on the same

522 order of magnitude as PFOS in select individuals (Fig. 1b inset). PFEA concentrations

523 were not correlated with PFOS or long-chain PFCAs in CFRE chicks, while PFO 5 DoDA

524 displayed a weak positive correlation with PFDA (Fig. S5). This lack of correlation 
525 suggests legacy PFAAs like PFOS were contributed to the system via different 526 pathways unassociated with the industrial facility producing PFEAs, in-line with their

527 previous detection in surface waters from the region ${ }^{53}$. Prior research indicates

528 concentrations of PFCAs and PFSAs in surface water are similar above and below the

529 fluoropolymer facility in Fayetteville, NC while concentrations of PFEAs varied starkly

530 upstream and downstream of the facility while active discharges from the facility were 531 ongoing $53,90$.

Implications for further research

534 Our results highlight the potential role of seabirds as key sentinels of marine

535 environments, and confirm the sustained presence of legacy PFAS in marine systems

536 along the US East Coast. We also document PFEAs in seabirds for the first time,

537 reflecting the shifting suite of PFAS in production and in environmental matrices. As our

538 current understanding of PFAS effects in wildlife is limited, future biomonitoring in

539 seabirds and other wildlife should derive responses and effects related to ambient

540 PFAS levels. Understanding PFAS levels and effects in marine food webs and biota

541 ultimately stands to benefit public health and commerce as we continue to rely on

542 marine food webs for economic, nutritional, and aesthetic services. 


\section{ASSOCIATED CONTENT}

544 The following files are available free of charge.

545 Details about sample preparation, extraction methods, instrumental analysis, quality

546 assurance and quality control, supplementary figures (PDF)

547 Monitored ions, extraction performance, raw data, summary statistics, data inputs for

548 comparison and BAF calculations (Excel workbook)

549 AUTHOR INFORMATION

550 Corresponding Author

551 *Anna Ruth Robuck, annarobuck@gmail.com

\section{Author Contributions}

553 The manuscript was primarily drafted by A. Robuck and finalized through contributions

554 of all authors. Sample analysis and data interpretation were carried out by A. Robuck

555 through contributions of all authors. All authors have given approval to the final version

556 of the manuscript.

\section{Funding Sources}

558 A. Robuck acknowledges support from the National Oceanic and Atmospheric

559 Administration Dr. Nancy Foster Scholarship program (NOAA Award Number

560 NA17NOS4290028), the Robert and Patricia Switzer Foundation, the STEEP Superfund

561 Research Program (NIEHS Award Number P42ES027706), and the Oak Ridge Institute 562 for Science and Education (ORISE) program. 
565 The authors are indebted to the Northeast Fisheries Observer Program, Gina Shield,

566 Johanna Pedersen, Michael Moore, Matthew Mclver, Marissa Sprouls, Arianna

567 Mouradjian, and the Wildlife Clinic of Rhode Island for assistance obtaining and

568 necropsying bird samples used in this study. The authors also acknowledge Christine

569 Gardiner (URI) for laboratory assistance and Michael A. Mallin for context about the

570 Cape Fear River and Estuary. We also acknowledge Melanie Hedgespeth, Andy

571 Lindstrom, and Elsie Sunderland for providing pre-submission critical reviews. Although

572 EPA and NOAA employees contributed to this article, this research was not funded by

573 EPA and was conceived, designed, and implemented by URI. The primary author was

574 not an ORISE participant at US EPA when the research was carried out. EPA's role was

575 limited to advising PFAS and stable isotope analysis and therefore not subject to EPA's

576 quality requirements. Consequently, the views, interpretations, and conclusions

577 expressed in the article are solely those of the authors and do not necessarily reflect or

578 represent NOAA or EPA's views or policies.

ABBREVIATIONS

PFAS: per- and polyfluoroalkyl substances

CFRE: Cape Fear River and Estuary

PFCAs: perfluoroalkyl carboxylate(s)

PFSAs: perfluoroalkyl sulfonates(s)

PFEAs: perfluoroalkyl ether acid(s)

PFECAs: perfluoroalkyl ether carboxylate(s)

PFESAs: perfluoroalkyl ether sulfonate(s)

BCF: bioconcentration factor

See SI Table S1 for the full names of all individual PFAS discussed in the scope of this analysis 
595

596

597
FOR TABLE OF CONTENTS ONLY

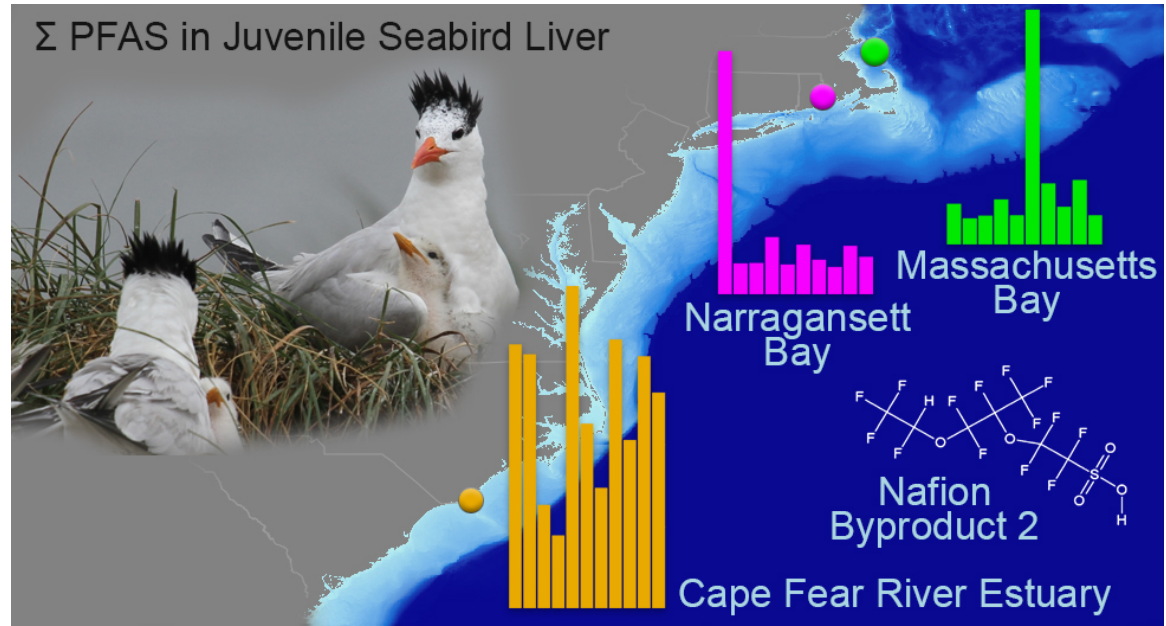


601

602

603

604

605

606

607

608

609

610

611

612

613

614

615

616

617

618

619

\section{REFERENCES}

(1) Buck, R. C.; Franklin, J.; Berger, U.; Conder, J. M.; Cousins, I. T.; Voogt, P. De; Jensen, A. A.; Kannan, K.; Mabury, S. A.; van Leeuwen, S. P. J. Perfluoroalkyl and Polyfluoroalkyl Substances in the Environment: Terminology, Classification, and Origins. Integr. Environ. Assess. Manag. 2011, 7 (4), 513-541.

https://doi.org/10.1002/ieam.258.

(2) Ahrens, L. Polyfluoroalkyl Compounds in the Aquatic Environment: A Review of Their Occurrence and Fate. J. Environ. Monit. 2011, 13 (1), 20-31. https://doi.org/10.1039/c0em00373e.

(3) Giesy, J. P.; Kannan, K. Global Distribution of Perfluorooctane Sulfonate in Wildlife Global Distribution of Perfluorooctane Sulfonate in Wildlife. Environ. Sci. Technol. 2001, 35 (March), 1339-1342. https://doi.org/10.1021/es001834k.

(4) Muir, D.; Bossi, R.; Carlsson, P.; Evans, M.; De Silva, A.; Halsall, C.; Rauert, C.; Herzke, D.; Hung, H.; Letcher, R.; Rigét, F.; Roos, A. Levels and Trends of Polyand Perfluoroalkyl Substances in the Arctic Environment - An Update. Emerg. Contam. 2019, 5, 240-271. https://doi.org/10.1016/j.emcon.2019.06.002.

(5) Wang, Z.; Dewitt, J. C.; Higgins, C. P.; Cousins, I. T. A Never-Ending Story of Per- and Polyfluoroalkyl Substances (PFASs)? Environ. Sci. Technol. 2017, 51 (5), 2508-2518. https://doi.org/10.1021/acs.est.6b04806.

(6) Liu, Y.; Agostino, L. A. D.; Qu, G.; Jiang, G.; Martin, J. W. High-Resolution Mass Spectrometry (HRMS) Methods for Nontarget Discovery and Characterization of 
620

621

622

623

624

625

626

627

628

629

630

631

632

633

634

635

636

637

638

639

640

Poly- and Per-Fluoroalkyl Substances (PFASs) in Environmental and Human

Samples. Trends Anal. Chem. 2019. https://doi.org/10.1016/j.trac.2019.02.021.

(7) Martin, J. W.; Asher, B. J.; Beesoon, S.; Benskin, J. P.; Ross, M. S. PFOS or PreFOS? Are Perfluorooctane Sulfonate Precursors (PreFOS) Important Determinants of Human and Environmental Perfluorooctane Sulfonate (PFOS) Exposure? J. Environ. Model. 2010, 12, 1979-2004.

https://doi.org/10.1039/c0em00295j.

(8) Mccord, J.; Strynar, M. Identification of Per- and Polyfluoroalkyl Substances in the Cape Fear River by High Resolution Mass Spectrometry and Nontargeted Screening. Environ. Sci. Technol. 2019, 53 (9), 4717-4727. https://doi.org/10.1021/acs.est.8b06017.

(9) Zhang, X.; Lohmann, R.; Dassuncao, C.; Hu, X. C.; Weber, A. K.; Vecitis, C. D.; Sunderland, E. M. Source Attribution of Poly- and Perfluoroalkyl Substances (PFASs) in Surface Waters from Rhode Island and the New York Metropolitan Area. Environ. Sci. Technol. Lett. 2016, 3 (9), 316-321. https://doi.org/10.1021/acs.estlett.6b00255.

(10) Falk, S.; Stahl, T.; Fliedner, A.; Rüdel, H.; Tarricone, K.; Brunn, H.; Koschorreck, J. Levels, Accumulation Patterns and Retrospective Trends of Perfluoroalkyl Acids (PFAAs) in Terrestrial Ecosystems over the Last Three Decades. Environ. Pollut. 2019, 246, 921-931. https://doi.org/10.1016/j.envpol.2018.12.095.

(11) Yamashita, N.; Taniyasu, S.; Petrick, G.; Wei, S.; Gamo, T.; Lam, P. K. S.; 
641

642

643

644

645

646

647

648

649

650

651

652

653

654

655

656

657

658

659

660

661

662

Kannan, K. Perfluorinated Acids as Novel Chemical Tracers of Global Circulation of Ocean Waters. Chemosphere 2008, 70 (7), 1247-1255.

https://doi.org/10.1016/j.chemosphere.2007.07.079.

(12) Munoz, G.; Budzinski, H. H.; Labadie, P. Influence of Environmental Factors on the Fate of Legacy and Emerging Per- and Polyfluoroalkyl Substances along the Salinity/Turbidity Gradient of a Macrotidal Estuary. Environ. Sci. Technol. 2017, 51 (21), acs.est.7b03626. https://doi.org/10.1021/acs.est.7b03626.

(13) Eriksson, U.; Roos, A.; Lind, Y.; Hope, K.; Ekblad, A.; Kärrman, A. Comparison of PFASs Contamination in the Freshwater and Terrestrial Environments by Analysis of Eggs from Osprey (Pandion Haliaetus), Tawny Owl (Strix Aluco), and Common Kestrel (Falco Tinnunculus). Environ. Res. 2016, 149, 40-47. https://doi.org/10.1016/j.envres.2016.04.038.

(14) Pickard, H. M.; Criscitiello, A. S.; Spencer, C.; Sharp, M. J.; Muir, D. C. G.; De Silva, A. O.; Young, C. J. Continuous Non-Marine Inputs of per- and Polyfluoroalkyl Substances to the High Arctic: A Multi-Decadal Temporal Record. Atmos. Chem. Phys. 2018, 18 (7), 5045-5058. https://doi.org/10.5194/acp-185045-2018.

(15) Ellis, D. A.; Martin, J. W.; Silva, A. O. D. E.; Hurley, M. D.; De Silva, A. O.; Mabury, S. A.; Hurley, M. D.; Sulbaek Andersen, M. P.; Wallington, T. J. Degradation of Fluorotelomer Alcohols: A Likely Atmospheric Source of Perfluorinated Carboxylic Acids. Environ. Sci. Technol. 2004, 38 (12), 3316-3321. https://doi.org/10.1021/es049860w. 
663 (16) Langberg, H. A.; Breedveld, G. D.; Grønning, H. M.; Kvennås, M.; Jenssen, B. M.; Hale, S. E. Bioaccumulation of Fluorotelomer Sulfonates and Perfluoroalkyl Acids

(20) Roscales, J. L.; Vicente, A.; Ryan, P. G.; González-Solís, J.; Jiménez, B. Spatial

(17) White, N. D.; Vena, J. E.; Kannan, K.; Karthikraj, R.; Wolf, B.; Fair, P. A.; Arnott, S. A. Perfluoroalkyl Substances (PFASs) in Edible Fish Species from Charleston Harbor and Tributaries, South Carolina, United States: Exposure and Risk Assessment. Environ. Res. 2019, 171 (November 2018), 266-277. https://doi.org/10.1016/j.envres.2019.01.021.

(18) Sun, J.; Bossi, R.; Bustnes, J. O.; Helander, B.; Boertmann, D.; Dietz, R.; Herzke, D.; Jaspers, V. L. B.; Labansen, A. L.; Lepoint, G.; Schulz, R.; Sonne, C.; Thorup, K.; Tøttrup, A. P.; Zubrod, J. P.; Eens, M.; Eulaers, I. White-Tailed Eagle (Haliaeetus Albicilla) Body Feathers Document Spatiotemporal Trends of Perfluoroalkyl Substances in the Northern Environment. Environ. Sci. Technol. 2019. https://doi.org/10.1021/acs.est.9b03514.

(19) Russell, M. C.; Newton, S. R.; McClure, K. M.; Levine, R. S.; Phelps, L. P.; Lindstrom, A. B.; Strynar, M. J. Per- and Polyfluoroalkyl Substances in Two Different Populations of Northern Cardinals. Chemosphere 2019, 222, 295-304. https://doi.org/10.1016/j.chemosphere.2019.01.112. and Interspecies Heterogeneity in Concentrations of Perfluoroalkyl Substances 
(PFASs) in Seabirds of the Southern Ocean. Environ. Sci. Technol. 2019, 53 (16), 9855-9865. https://doi.org/10.1021/acs.est.9b02677.

(21) Miller, A.; Elliott, J. E.; Elliott, K. H.; Lee, S.; Cyr, F. Temporal Trends of Perfluoroalkyl Substances (PFAS) in Eggs of Coastal and Offshore Birds: Increasing PFAS Levels Associated with Offshore Bird Species Breeding on the Pacific Coast of Canada and Wintering near Asia. Environ. Toxicol. Chem. 2015, 34 (8), 1799-1808. https://doi.org/10.1002/etc.2992.

(22) Dassuncao, C.; Hu, X. C.; Zhang, X.; Bossi, R.; Dam, M.; Mikkelsen, B.; Sunderland, E. M. Temporal Shifts in Poly- and Perfluoroalkyl Substances (PFASs) in North Atlantic Pilot Whales Indicate Large Contribution of Atmospheric Precursors. Environ. Sci. Technol. 2017, 51 (8), 4512-4521. https://doi.org/10.1021/acs.est.7b00293.

(23) Ahrens, L.; Bundschuh, M.; Hrens, L. U. T. Z. A.; Undschuh, M. I. B. Fate and Effects of Poly- and Perfluoroalkyl Substances in the Aquatic Environment: A Review. Environ. Toxicol. Chem. 2014, 33 (9), 1921-1929. https://doi.org/10.1002/etc.2663.

(24) Gomis, M. I.; Vestergren, R.; Borg, D.; Cousins, I. T. Comparing the Toxic Potency in Vivo of Long-Chain Perfluoroalkyl Acids and Fluorinated Alternatives. Environ. Int. 2018, 113 (November 2017), 1-9. https://doi.org/10.1016/j.envint.2018.01.011.

(25) Blévin, P.; Tartu, S.; Ellis, H. I.; Chastel, O.; Bustamante, P.; Parenteau, C.; 
Herzke, D.; Angelier, F.; Gabrielsen, G. W. Contaminants and Energy Expenditure in an Arctic Seabird: Organochlorine Pesticides and Perfluoroalkyl Substances Are Associated with Metabolic Rate in a Contrasted Manner. Environ. Res. 2017, 157 (February), 118-126.

https://doi.org/10.1016/j.envres.2017.05.022.

(26) Cassone, C. G.; Vongphachan, V.; Chiu, S.; Williams, K. L.; Letcher, R. J.; Pelletier, E.; Crump, D.; Kennedy, S. W. In Ovo Effects of Perfluorohexane Sulfonate and Perfluorohexanoate on Pipping Success, Development, MRNA Expression, and Thyroid Hormone Levels in Chicken Embryos. Toxicol. Sci. 2012, 127 (1), 216-224. https://doi.org/10.1093/toxsci/kfs072.

(27) Peden-Adams, M. M.; Stuckey, J. E.; Gaworecki, K. M.; Berger-Ritchie, J.; Bryant, K.; Jodice, P. G.; Scott, T. R.; Ferrario, J. B.; Guan, B.; Vigo, C.; Boone, J. S.; McGuinn, W. D.; DeWitt, J. C.; Keil, D. E. Developmental Toxicity in White Leghorn Chickens Following in Ovo Exposure to Perfluorooctane Sulfonate (PFOS). Reprod. Toxicol. 2009, 27 (3-4), 307-318.

https://doi.org/10.1016/j.reprotox.2008.10.009.

(28) Costantini, D.; Blévin, P.; Herzke, D.; Moe, B.; Wing, G.; Ove, J.; Chastel, O.; Gabrielsen, G. W.; Bustnes, J. O.; Chastel, O. Higher Plasma Oxidative Damage and Lower Plasma Antioxidant Defences in an Arctic Seabird Exposed to Longer Perfluoroalkyl Acids. Environ. Res. 2019, 168 (October 2018), 278-285. https://doi.org/10.1016/j.envres.2018.10.003.

(29) Custer, C. M.; Custer, T. W.; Dummer, P. M.; Etterson, M. A.; Mckann, P. C. 
Exposure and Effects of Perfluoroalkyl Substances in Tree Swallows Nesting in Minnesota and Wisconsin , USA. 2014, 2000, 120-138.

https://doi.org/10.1007/s00244-013-9934-0.

(30) Lopez-Antia, A.; Groffen, T.; Lasters, R.; AbdElgawad, H.; Sun, J.; Asard, H.; Bervoets, L.; Eens, M. Perfluoroalkyl Acids (PFAAs) Concentrations and Oxidative Status in Two Generations of Great Tits Inhabiting a Contamination Hotspot. Environ. Sci. Technol. 2019, 53, 1617-1626.

https://doi.org/10.1021/acs.est.8b05235.

(31) Nordén, M.; Berger, U.; Engwall, M. Developmental Toxicity of PFOS and PFOA in Great Cormorant ( Phalacrocorax Carbo Sinensis ), Herring Gull ( Larus Argentatus ) and Chicken ( Gallus Gallus Domesticus ). 2016, 10855-10862. https://doi.org/10.1007/s11356-016-6285-1.

(32) Geng, D.; Musse, A. A.; Wigh, V.; Carlsson, C.; Engwall, M.; Orešič, M.;

Scherbak, N.; Hyötyläinen, T. Effect of Perfluorooctanesulfonic Acid (PFOS) on the Liver Lipid Metabolism of the Developing Chicken Embryo. Ecotoxicol. Environ. Saf. 2019, 170 (October 2018), 691-698.

https://doi.org/10.1016/j.ecoenv.2018.12.040.

(33) Jacobsen, A. V.; Nordén, M.; Engwall, M.; Scherbak, N. Effects of Perfluorooctane Sulfonate on Genes Controlling Hepatic Fatty Acid Metabolism in Livers of Chicken Embryos. Environ. Sci. Pollut. Res. 2018, 25 (23), 2307423081. https://doi.org/10.1007/s11356-018-2358-7. 
749

750

751

752

753

754

755

756

757

758

759

760

761

762

763

764

765

766

767

768

769

770

(34) Salihovic, S.; Fall, T.; Ganna, A.; Broeckling, C. D.; Prenni, J. E.; Hyötyläinen, T.; Kärrman, A.; Lind, P. M.; Ingelsson, E.; Lind, L. Identification of Metabolic Profiles Associated with Human Exposure to Perfluoroalkyl Substances. J. Expo. Sci. Environ. Epidemiol. 2019, 29 (2), 196-205. https://doi.org/10.1038/s41370-0180060-y.

(35) Kelly, B. C.; Ikonomou, M. G.; Blair, J. D.; Surridge, B.; Hoover, D.; Grace, R.; Gobas, F. A. P. C. Perfluoroalkyl Contaminants in an Arctic Marine Food Web: Trophic Magnification and Wildlife Exposure. Environ. Sci. Technol. 2009, 43 (11), 4037-4043. https://doi.org/10.1021/es9003894.

(36) Munoz, G.; Budzinski, H. H.; Babut, M.; Drouineau, H.; Lauzent, M.; Menach, K. Le; Lobry, J.; Selleslagh, J.; Simonnet-Laprade, C.; Labadie, P. Evidence for the Trophic Transfer of Perfluoroalkylated Substances in a Temperate Macrotidal Estuary. Environ. Sci. Technol. 2017, 51 (15), 8450-8459. https://doi.org/10.1021/acs.est.7b02399.

(37) Loi, E. I. H.; Yeung, L. W. Y.; Taniyasu, S.; Lam, P. K. S.; Kannan, K.; Yamashita, N. Trophic Magnification of Poly- and Perfluorinated Compounds in a Subtropical Food Web. Environ. Sci. Technol. 2011, 45 (13), 5506-5513. https://doi.org/10.1021/es200432n.

(38) Groffen, T.; Lopez-Antia, A.; Hollander, W. D.; Prinsen, E.; Eens, M. Perfluoroalkylated Acids in the Eggs of Great Tits ( Parus Major ) near a Flurochemical Plant in Flanders, Belgium. Environ. Pollut. 2017, 228, 140-148. https://doi.org/10.1016/j.envpol.2017.05.007. 
771 (39) Piatt, J. F.; Sydeman, W. J.; Wiese, F. Introduction: A Modern Role for Seabirds

772

773

774

775

776

777

778

779

780

781

782

783

784

785

786

787

788

789

790 as Indicators. Mar. Ecol. Prog. Ser. 2007, 352, 199-204. https://doi.org/10.3354/meps07070.

(40) Cairns, D. K. Seabirds as Indicators of Marine Food Supplies. Biol. Oceanogr. 1987, 5 (June), 261-271. https://doi.org/10.1080/01965581.1987.10749517.

(41) Furness, R. W.; Camphuysen, K. Seabirds as Monitors of the Marine Environment. ICES J. Mar. Sci. 1997, 54 (4), 726-737. https://doi.org/10.1006/jmsc.1997.0243.

(42) Hobson, K. A.; Piatt, J. F.; Pitocchelli, J. Using Stable Isotopes to Determine Seabird Trophic Relationships. J. Anim. Ecol. 1994, 63 (4), 786-798.

(43) Hazen, E. L.; Abrahms, B.; Brodie, S.; Carroll, G.; Jacox, M. G.; Savoca, M. S.; Scales, K. L.; Sydeman, W. J.; Bograd, S. J. Marine Top Predators as Climate and Ecosystem Sentinels. 2019, 1-10. https://doi.org/10.1002/fee.2125.

(44) Lopez-Antia, A.; Dauwe, T.; Meyer, J.; Maes, K.; Bervoets, L.; Eens, M. High Levels of PFOS in Eggs of Three Bird Species in the Neighbourhood of a FluoroChemical Plant. Ecotoxicol. Environ. Saf. 2020, 139 (August 2016), 165-171. https://doi.org/10.1016/j.ecoenv.2017.01.040.

(45) Yoo, H.; Kannan, K.; Seong, K. K.; Kyu, T. L.; Newsted, J. L.; Giesy, J. P. Perfluoroalkyl Acids in the Egg Yolk of Birds from Lake Shihwa, Korea. Environ. Sci. Technol. 2008, 42 (15), 5821-5827. https://doi.org/10.1021/es800447d. 
791

792

793

794

795

796

797

798

799

800

801

802

803

804

805

806

807

808

809

810

811

(46) Newsted, J. L.; Coady, K. K.; Beach, S. A.; Butenhoff, J. L.; Gallagher, S.; Giesy, J. P. Effects of Perfluorooctane Sulfonate on Mallard and Northern Bobwhite Quail Exposed Chronically via the Diet. Environ. Toxicol. Pharmacol. 2007, 23 (1), 1-9. https://doi.org/10.1016/j.etap.2006.04.008.

(47) Holmström, K. E.; Berger, U. Tissue Distribution of Perfluorinated Surfactants in Common Guillemot (Uria Aalge) from the Baltic Sea. Environ. Sci. Technol. 2008, 42 (16), 5879-5884. https://doi.org/10.1021/es800529h.

(48) Wang, J.; Zhang, Y.; Zhang, F.; Yeung, L. W. Y.; Taniyasu, S.; Yamazaki, E.; Wang, R.; Lam, P. K. S.; Yamashita, N.; Dai, J. Age- and Gender-Related Accumulation of Perfluoroalkyl Substances in Captive Chinese Alligators (Alligator Sinensis). Environ. Pollut. 2013, 179, 61-67. https://doi.org/10.1016/j.envpol.2013.04.020.

(49) van Franeker, J. A. Save the North Sea Fulmar-Litter-EcoQO Manual - Part 1: Collection and Dissection Procedures. Alterra-rapport 2004, 672, 1-38.

(50) Kannan, K.; Choi, J. W.; Iseki, N.; Senthilkumar, K.; Hoon, D.; Masunaga, S.; Giesy, J. P.; Kim, D. H.; Masunaga, S.; Giesy, J. P. Concentrations of Perfluorinated Acids in Livers of Birds from Japan and Korea. Chemosphere 2002, 49 (3), 225-231. https://doi.org/10.1016/S0045-6535(02)00304-1.

(51) Guruge, K. S.; Yeung, L. W. Y.; Li, P.; Taniyasu, S.; Yamashita, N.; Nakamura, M. Fluorinated Alkyl Compounds Including Long Chain Carboxylic Acids in Wild Bird Livers from Japan. Chemosphere 2011, 83 (3), 379-384. 
https://doi.org/10.1016/j.chemosphere.2010.12.010.

813

814

815

816

817

818

819

820

821

822

823

824

825

826

827

828

829

830

831

832

(52) Guillette, T. C. T.; McCord, J.; Guillette, M.; Polera, M. E.; Rachels, K. T.;

Morgeson, C.; Kotlarz, N.; Knappe, D. R. U.; Reading, B. J.; Strynar, M.; Belcher,

S. M. Per- and Polyfluoroalkyl Substances Exposure in Cape Fear River Striped

Bass (Morone Saxatilis) Is Associated with Biomarkers of Altered Immune and

Liver Function Research. Environ. Int. 2019, 136 (September), 105358.

https://doi.org/10.1016/j.envint.2019.105358.

(53) Strynar, M.; Dagnino, S.; McMahen, R.; Liang, S.; Lindstrom, A.; Andersen, E.; McMillan, L.; Thurman, M.; Ferrer, I.; Ball, C. Identification of Novel Perfluoroalkyl Ether Carboxylic Acids (PFECAs) and Sulfonic Acids (PFESAs) in Natural Waters Using Accurate Mass Time-of-Flight Mass Spectrometry (TOFMS). Environ. Sci. Technol. 2015, 49 (19), 11622-11630. https://doi.org/10.1021/acs.est.5b01215.

(54) Dassuncao, C.; Pickard, H.; Pfohl, M.; Tokranov, A. K.; Li, M.; Mikkelsen, B.; Slitt, A.; Sunderland, E. M. Phospholipid Levels Predict the Tissue Distribution of Polyand Perfluoroalkyl Substances in a Marine Mammal. Environ. Sci. Technol. Lett. 2019, 6 (3), acs.estlett.9b00031. https://doi.org/10.1021/acs.estlett.9b00031.

(55) R Core Team. R: A Language and Environment for Statistical Computing. R Foundation for Statistical Computing: Vienna, Austria 2020.

(56) Hites, R. A. Correcting for Censored Environmental Measurements. Environ. Sci. Technol. 2019, 53 (19), 11059-11060. https://doi.org/10.1021/acs.est.9b05042.

(57) Conder, J. M.; Hoke, R. A.; Wolf, W.; Russell, M. H.; Buck, R. C. Are PFCAs 
Bioaccumulative? A Critical Review and Comparison with Regulatory Criteria and Persistent Lipophilic Compounds. Environ. Sci. Technol. 2008, 42, 995-1003.

(58) Liu, J.; Mejia Avendaño, S. Microbial Degradation of Polyfluoroalkyl Chemicals in the Environment: A Review. Environ. Int. 2013, 61, 98-114. https://doi.org/10.1016/j.envint.2013.08.022.

(59) Sedlak, M. D.; Benskin, J. P.; Wong, A.; Grace, R.; Greig, D. J. Per- and Polyfluoroalkyl Substances (PFASs) in San Francisco Bay Wildlife : Temporal Trends, Exposure Pathways, and Notable Presence of Precursor Compounds. Chemosphere 2017, 185, 1217-1226. https://doi.org/10.1016/j.chemosphere.2017.04.096.

(60) Leat, E. H. K.; Bourgeon, S.; Eze, J. I.; Muir, D. C. G.; Williamson, M.; Bustnes, J. O.; Furness, R. W.; Borgå, K. Perfluoroalkyl Substances in Eggs and Plasma of an Avian Top Predator, Great Skua (Stercorarius Skua), in the North Atlantic. Environ. Toxicol. Chem. 2013, 32 (3), 569-576. https://doi.org/10.1002/etc.2101.

(61) Chu, S.; Wang, J.; Leong, G.; Ann, L.; Letcher, R. J.; Li, Q. X.; Woodward, L. A.; Letcher, R. J.; Li, Q. X. Perfluoroalkyl Sulfonates and Carboxylic Acids in Liver, Muscle and Adipose Tissues of Black-Footed Albatross (Phoebastria Nigripes) from Midway Island, North Pacific Ocean. Chemosphere 2015, 138 (2015), 6066. https://doi.org/10.1016/j.chemosphere.2015.05.043.

(62) Letcher, R. J.; Su, G.; Moore, J. N.; Williams, L. L.; Martin, P. A.; De Solla, S. R.; Bowerman, W. W.; Solla, S. R. De; Bowerman, W. W. Perfluorinated Sulfonate 
and Carboxylate Compounds and Precursors in Herring Gull Eggs from across the Laurentian Great Lakes of North America: Temporal and Recent Spatial Comparisons and Exposure Implications. Sci. Total Environ. 2015, 538 (August), 468-477. https://doi.org/10.1016/j.scitotenv.2015.08.083.

(63) Braune, B. M.; Letcher, R. J. Perfluorinated Sulfonate and Carboxylate Compounds in Eggs of Seabirds Breeding in the Canadian Arctic: Temporal Trends (1975-2011) and Interspecies Comparison. Environ. Sci. Technol. 2013, 47 (1), 616-624. https://doi.org/10.1021/es303733d.

(64) Newsted, J. L.; Jones, P. D.; Coady, K.; Giesy, J. P. Avian Toxicity Reference Values for Perfluorooctane Sulfonate. Environ. Sci. Technol. 2005, 39 (23), 93579362. https://doi.org/10.1021/es050989v.

(65) Armitage, J. M.; Schenker, U.; Scheringer, M.; Martin, J. W.; Macleod, M.; Cousins, I. T. Modeling the Global Fate and Transport of Perfluorooctane Sulfonate (PFOS) and Precursor Compounds in Relation to Temporal Trends in Wildlife Exposure. Environ. Sci. Technol. 2009, 43 (24), 9274-9280. https://doi.org/10.1021/es901448p.

(66) Gebbink, W. A.; Letcher, R. J.; Hebert, C. E.; Chip Weseloh, D. V. V. Twenty Years of Temporal Change in Perfluoroalkyl Sulfonate and Carboxylate Contaminants in Herring Gull Eggs from the Laurentian Great Lakes. J. Environ. Monit. 2011, 13 (12), 3365-3372. https://doi.org/10.1039/c1em10663e.

(67) Tarazona, J. V.; Rodríguez, C.; Alonso, E.; Sáez, M.; González, F.; San Andrés, 
875

876

877

878

879

880

881

882

883

884

885

886

887

888

889

890

891

892

893

894

895

896

M. D.; Jiménez, B.; San Andrés, M. I. Toxicokinetics of Perfluorooctane Sulfonate in Birds under Environmentally Realistic Exposure Conditions and Development of a Kinetic Predictive Model. Toxicol. Lett. 2015, 232 (2), 363-368.

https://doi.org/10.1016/j.toxlet.2014.11.022.

(68) Yoo, H.; Guruge, K. S.; Yamanaka, N.; Sato, C.; Mikami, O.; Miyazaki, S.; Yamashita, N.; Giesy, J. P. Depuration Kinetics and Tissue Disposition of PFOA and PFOS in White Leghorn Chickens (Gallus Gallus) Administered by Subcutaneous Implantation. Ecotoxicol. Environ. Saf. 2009, 72 (1), 26-36. https://doi.org/10.1016/j.ecoenv.2007.09.007.

(69) Routti, H.; Aars, J.; Fuglei, E.; Hanssen, L.; Lone, K.; Polder, A.; Pedersen, A. Ø.; Tartu, S.; Welker, M.; Yoccoz, N. G. Emission Changes Dwarf the In FI Uence of Feeding Habits on Temporal Trends of Per- and Poly FI Uoroalkyl Substances in Two Arctic Top Predators. 2017. https://doi.org/10.1021/acs.est.7b03585.

(70) Martin, J. W.; Smithwick, M. M.; Braune, B. M.; Hoekstra, P. F.; Muir, D. C. G.; Mabury, S. A. Identification of Long-Chain Perfluorinated Acids in Biota from the Canadian Arctic. Environ. Sci. Technol. 2004, 38 (2), 373-380. https://doi.org/10.1021/es034727+.

(71) Armitage, J. M.; MacLeod, M.; Cousins, I. T. Modeling the Global Fate and Transport of Perfluorooctanoic Acid (PFOA) and Perfluorooctanoate (PFO) Emitted from Direct Sources Using a Multispecies Mass Balance Model (Environmental Science and Technology (2009) 43, 1134-1140)). Environ. Sci. Technol. 2009, 43 (16), 6438-6439. https://doi.org/10.1021/es901832b. 
897 (72) Conder, J. M.; Hoke, R. A.; De Wolf, W.; Russell, M. H.; Buck, R. C. Are PFCAs Bioaccumulative? A Critical Review and Comparison with Regulatory Criteria and Persistent Lipophilic Compounds. Environ. Sci. Technol. 2008, 42 (4), 995-1003. https://doi.org/10.1021/es070895g.

901

(73) Tartu, S.; Gabrielsen, G. W.; Blévin, P.; Ellis, H.; Bustnes, J. O.; Herzke, D.; Chastel, O. Endocrine and Fitness Correlates of Long-Chain Perfluorinated Carboxylates Exposure in Arctic Breeding Black-Legged Kittiwakes. Environ. Sci. Technol. 2014, 48 (22), 13504-13510. https://doi.org/10.1021/es503297n.

(74) Crain, C. M.; Kroeker, K.; Halpern, B. S. Interactive and Cumulative Effects of Multiple Human Stressors in Marine Systems. Ecol. Lett. 2008, 11 (12), 13041315. https://doi.org/10.1111/j.1461-0248.2008.01253.x.

(75) Campioni, L.; Granadeiro, J. P.; Catry, P. Niche Segregation between Immature and Adult Seabirds: Does Progressive Maturation Play a Role? Behav. Ecol. 2016, 27 (2), 426-433. https://doi.org/10.1093/beheco/arv167.

(76) Pizzurro, D. M.; Seeley, M.; Kerper, L. E.; Beck, B. D. Interspecies Differences in Perfluoroalkyl Substances (PFAS)Toxicokinetics and Application to Health-Based Criteria. Regul. Toxicol. Pharmacol. 2019, 106 (May), 239-250. https://doi.org/10.1016/j.yrtph.2019.05.008.

(77) Baduel, C.; Lai, F. Y.; Townsend, K.; Mueller, J. F. Size and Age-Concentration Relationships for Perfluoroalkyl Substances in Stingray Livers from Eastern Australia. Sci. Total Environ. 2014, 496, 523-530. 

https://doi.org/10.1016/j.scitotenv.2014.07.010.

919

920

921

922

923

924

925

926

927

928

929

930

931

932

933

934

935

936

937

938

(78) Mondal, D.; Lopez-Espinosa, M. J.; Armstrong, B.; Stein, C. R.; Fletcher, T. Relationships of Perfluorooctanoate and Perfluorooctane Sulfonate Serum Concentrations between Mother-Child Pairs in a Population with Perfluorooctanoate Exposure from Drinking Water. Environ. Health Perspect. 2012, 120 (5), 752-757. https://doi.org/10.1289/ehp.1104538.

(79) Ng, C. A.; Hungerbühler, K. Bioaccumulation of Perfluorinated Alkyl Acids: Observations and Models. Environ. Sci. Technol. 2014, 48 (9), 4637-4648. https://doi.org/10.1021/es404008g.

(80) Ng, C. A.; Hungerbühler, K. Bioconcentration of Perfluorinated Alkyl Acids: How Important Is Specific Binding? Environ. Sci. Technol. 2013, 47 (13), 7214-7223. https://doi.org/10.1021/es400981a.

(81) Armitage, J. M.; Arnot, J. A.; Wania, F. Potential Role of Phospholipids in Determining the Internal Tissue Distribution of Perfluoroalkyl Acids in Biota. Environ. Sci. Technol. 2012, 46 (22), 12285-12286. https://doi.org/10.1021/es304430r.

(82) Yeung, L. W. Y.; Guruge, K. S.; Yamanaka, N.; Miyazaki, S.; Lam, P. K. S. Differential Expression of Chicken Hepatic Genes Responsive to PFOA and PFOS. Toxicology 2007, 237 (1-3), 111-125. https://doi.org/10.1016/j.tox.2007.05.004.

(83) Ronconi, R. A.; Koopman, H. N.; McKinstry, C. A. E.; Wong, S. N. P.; Westgate, 
A. J. Inter-Annual Variability in Diet of Non-Breeding Pelagic Seabirds Puffinus

Spp. at Migratory Staging Areas: Evidence from Stable Isotopes and Fatty Acids. Mar. Ecol. Prog. Ser. 2010, 419, 267-282. https://doi.org/10.3354/meps08860.

942

943

944

945

946

947

948

949

950

951

952

953

954

955

956

957

958

959

(84) Calhoon, E. A. Lipid and Phospholipid Species Composition Associated with Life History Variation in North Temperate and Neotropical Birds, Ohio State University, 2016.

(85) Entenman, C. Lipid Content of Chick Tissues. J Biol Chem 1940, No. 65, $231-$ 241.

(86) Blem, C. R. Patterns of Lipid Storage and Utilization in Birds. Integr. Comp. Biol. 1976, 16 (4), 671-684. https://doi.org/10.1093/icb/16.4.671.

(87) Nouhi, S.; Ahrens, L.; Campos Pereira, H.; Hughes, A. V.; Campana, M.; Gutfreund, P.; Palsson, G. K.; Vorobiev, A.; Hellsing, M. S. Interactions of Perfluoroalkyl Substances with a Phospholipid Bilayer Studied by Neutron Reflectometry. J. Colloid Interface Sci. 2018, 511, 474-481. https://doi.org/10.1016/j.jcis.2017.09.102.

(88) Fitzgerald, N. J. M.; Wargenau, A.; Sorenson, C.; Pedersen, J.; Tufenkji, N.; Novak, P. J.; Simcik, M. F. Partitioning and Accumulation of Perfluoroalkyl Substances in Model Lipid Bilayers and Bacteria. Environ. Sci. Technol. 2018, 52 (18), 10433-10440. https://doi.org/10.1021/acs.est.8b02912.

(89) Fisk, A. T.; Hobson, K. A.; Norstrom, R. J. Influence of Chemical and Biological Factors on Trophic Transfer of Persistent Organic Pollutants in the Northwater 
Polynya Marine Food Web. Environ. Sci. Technol. 2001, 35 (4), 732-738. https://doi.org/10.1021/es001459w.

(90) Sun, M.; Arevalo, E.; Strynar, M.; Lindstrom, A.; Richardson, M.; Kearns, B.; Pickett, A.; Smith, C.; Knappe, D. R. U. Legacy and Emerging Perfluoroalkyl Substances Are Important Drinking Water Contaminants in the Cape Fear River Watershed of North Carolina. Environ. Sci. Technol. Lett. 2016, 3 (12), 415-419. https://doi.org/10.1021/acs.estlett.6b00398.

(91) Nakayama, S.; Strynar, M. J.; Helfant, L.; Egeghy, P.; Ye, X.; Lindstrom, A. B. Perfluorinated Compounds in the Cape Fear Drainage Basin in North Carolina. Environ. Sci. Technol. 2007, 41, 5271-5276. https://doi.org/10.1021/es070792y.

(92) Hopkins, Z. R.; Sun, M.; DeWitt, J. C.; Knappe, D. R. U. Recently Detected Drinking Water Contaminants : GenX and Other Per- and Polyfluoroalkyl Ether Acids. J. AWWA 2018, 110 (7), 13-28. https://doi.org/10.1002/awwa.1073.

(93) Sachs, E. Provisioning and Prey Quality in Brown Pelicans (Pelecanus Occidentalis) in Charleston Harbor, South Carolina, Clemson University, 2007.

(94) Baptist, M. J.; Leopold, M. F. Prey Capture Success of Sandwich Terns Sterna Sandvicensis Varies Non-Linearly with Water Transparency. Ibis (Lond. 1859). 2010, 152 (4), 815-825. https://doi.org/10.1111/j.1474-919X.2010.01054.x.

(95) Ronconi, R. A.; Steenweg, R. J.; Taylor, P. D.; Mallory, M. L. Gull Diets Reveal Dietary Partitioning, Influences of Isotopic Signatures on Body Condition, and Ecosystem Changes at a Remote Colony. Mar. Ecol. Prog. Ser. 2014, 514 
(August 2015), 247-261. https://doi.org/10.3354/meps10980.

982 (96) Zhang, C.; Hopkins, Z. R.; Mccord, J.; Strynar, M. J.; Detlef, R. U.; Knappe, D. R. U. Fate of Per- and Polyfluoroalkyl Ether Acids in the Total Oxidizable Precursor Assay and Implications for the Analysis of Impacted Water. Environ. Sci. Technol.

985 Lett. 2019. https://doi.org/10.1021/acs.estlett.9b00525.

986 (97) Feng, M.; Qu, R.; Wei, Z.; Wang, L.; Sun, P.; Wang, Z. Characterization of the 987 Thermolysis Products of Nafion Membrane : A Potential Source of Perfluorinated Compounds in the Environment. 2015, 1-8. https://doi.org/10.1038/srep09859.

989 (98) Mauritz, K. A.; Moore, R. B. State of Understanding of Nafion. Chem. Rev. 2004, 990 104 (10), 4535-4585. https://doi.org/10.1021/cr0207123. 